\title{
AN EXPLORATION OF FACTORS AFFECTING RETENTION AND PERSISTENCE OF UNDERGRADUATE MILITARY VETERAN STUDENTS AT THE UNIVERSITY OF MISSOURI
}

A Thesis
presented to
the Faculty of the Graduate School
at the University of Missouri-Columbia
In Partial Fulfillment
of the Requirements for the Degree
Master of Arts

MARTHA L. PICKENS

Dr. David Bergin, Thesis Supervisor

DECEMBER 2013 
The undersigned, appointed by the dean of the Graduate School, have examined the thesis entitled

\section{AN EXPLORATION OF FACTORS AFFECTING RETENTION AND PERSISTENCE OF UNDERGRADUATE MILITARY VETERAN STUDENTS AT THE UNIVERSITY OF MISSOURI}

presented by Martha L. Pickens,

a candidate for the degree of master of arts,

and hereby certify that, in their opinion, it is worthy of acceptance.

Professor David Bergin

Professor Jeni Hart

Professor Stephen Whitney 


\section{ACKNOWLEDGEMENTS}

Without the assistance of Dr. Jeni Hart I could not have completed this thesis. She spent hours helping me to shape my proposal and assisted me with substantial revisions of the thesis. Dr. Hart was extremely generous with her time and patience and I am forever in her debt. The editing suggestions of my advisor, Dr. David Bergin, inspired me to think more deeply about this work. Dr. Jessica Summers was my first advisor; I appreciate her early enthusiasm for my research area.

My supervisor at work, Dr. Esther Thorson, has gone the extra mile in supporting my efforts to obtain a graduate degree while working full time. My coworkers Ginny Cowell, Stephanie Craft, Margaret Duffy, George Kennedy, Amy Lenk and Sarah SmithFrigerio have also been a constant source of encouragement. Numerous friends lent support as well, including Robin Lipkin, who provided important technical assistance. My family - mother Juanice, sister Joanna and brother Greg - have always been in my corner, as was my late father, James. I am eternally grateful for their presence in my life.

Finally, my partner, Barb Sonderman, has provided both a carrot and a stick over the years as I have worked to complete my degree. Her encouragement, harassment, and faith in my abilities have kept me going, and I have promised her that I will not pursue a doctoral degree.... 


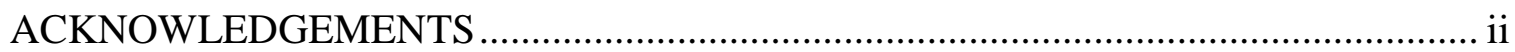

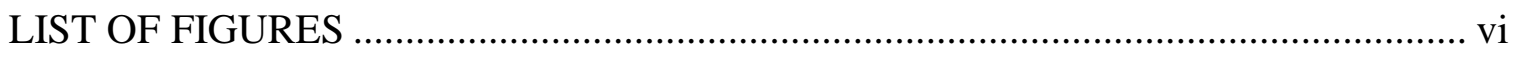

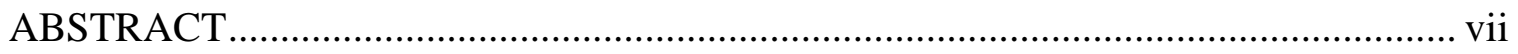

\section{Chapter}

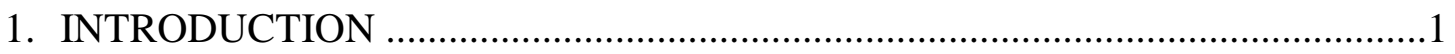

Statement of Problem .......................................................................................

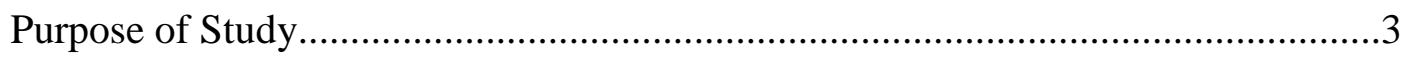

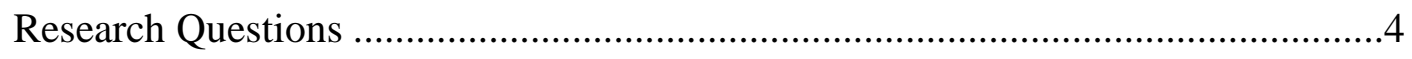

Definition of Terms …………………................................................................

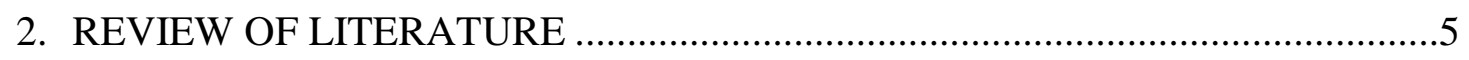

Theoretical Framework ………………...............................................................

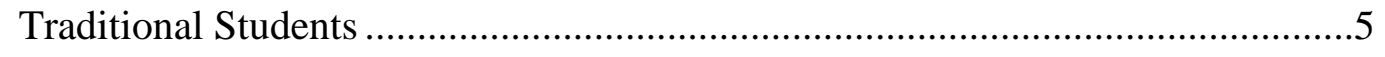

First-generation and Minority Students ...........................................................

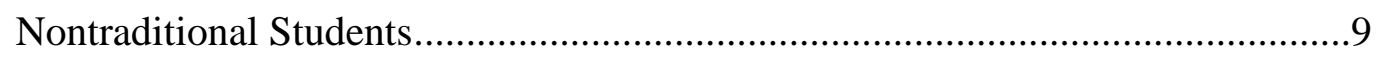

Research on Nontraditional Students Using Bean and Metzner Model................12

Tinto and Bean as Applied to Veteran Students ..................................................13

Military Veterans as Students ..............................................................................14

Support from the GI Bill ........................................................................14

Comparison with traditional and nontraditional students .............................16

Campus atmosphere and programmatic interventions ..................................17

Brief Profile of the University of Missouri ..............................................................20

Efforts by the University to Become a Veteran-Friendly Campus ...........................21 


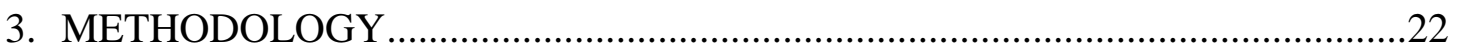

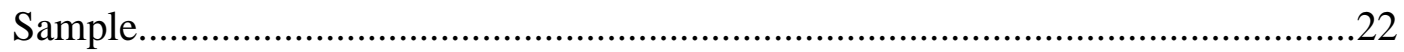

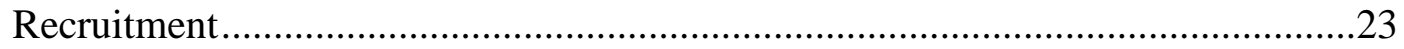

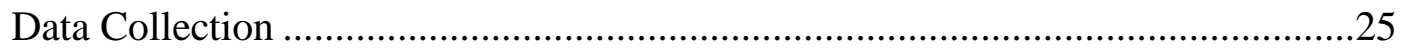

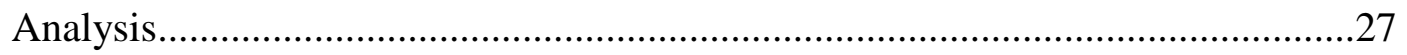

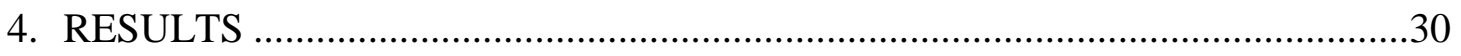

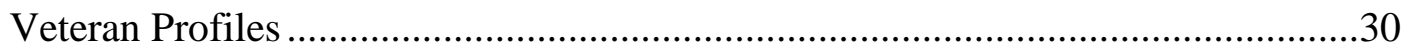

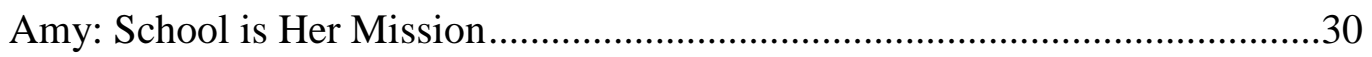

Andrew: Family First ........................................................................ 40

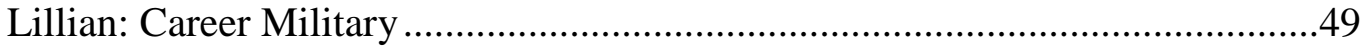

Scott: College is Harder Than He Thought......................................................54

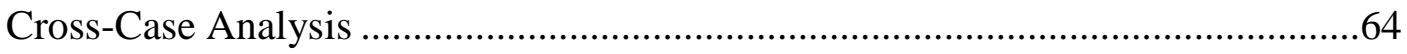

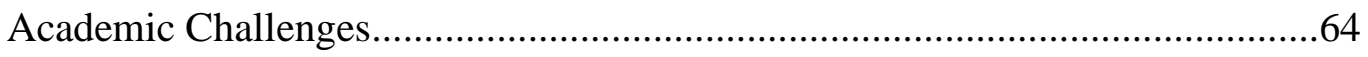

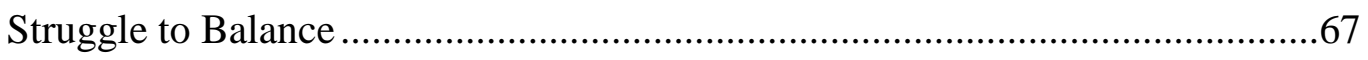

Transition to Civilian Life ................................................................... 71

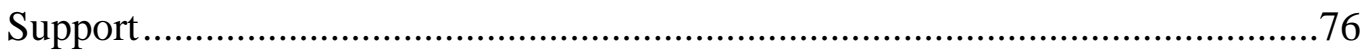

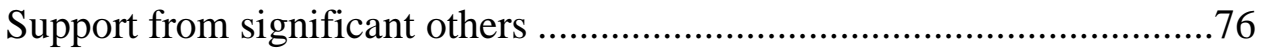

Support from the institution ..................................................................

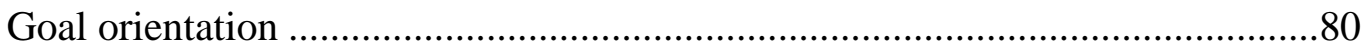

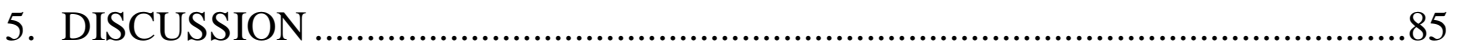

Personal Factors that Impede Persistence........................................................86

Personal Factors that Support Persistence ........................................................94

Institutional Factors that Support Persistence.................................................99

Institutional Factors that Impede Persistence .....................................................101 
Limitations of the Study.

Implications for Practice and Future Research ..................................................104

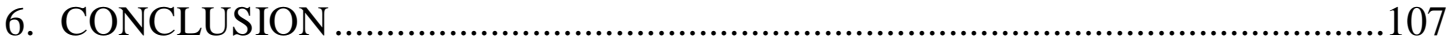

APPENDIX

A. VETERANS RESEARCH ELIGIBILITY SURVEY ........................................108

B. WAIVER OF DOCUMENTATION OF CONSENT .....................................109

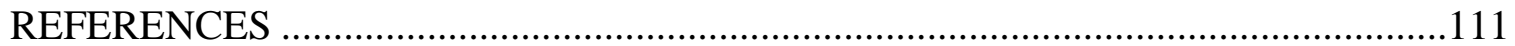




\section{LIST OF FIGURES}

Figure $\quad$ Page

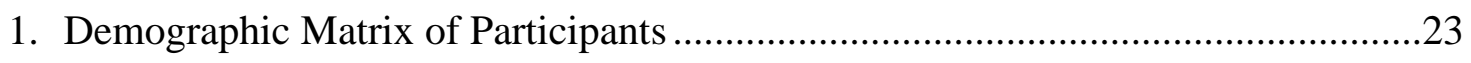




\title{
AN EXPLORATION OF FACTORS AFFECTING RETENTION AND PERSISTENCE OF UNDERGRADUATE MILITARY VETERAN STUDENTS AT THE UNIVERSITY OF MISSOURI
}

\author{
Martha L. Pickens
}

Dr. David Bergin, Thesis Supervisor

\begin{abstract}
Using the retention and persistence theories of Tinto and Bean as a framework, this qualitative multi-case study analyzed the personal and institutional factors that are assisting and impeding the persistence efforts of four undergraduate military veteran students at a large Midwestern university. Results indicate that all four students found the college experience to be much more difficult than they anticipated. Lack of preparation in high school, time away from the classroom, advances in technology, and a struggle to balance academic and other obligations were all cited as challenges. The personal development each student gained through military service was cited as making a positive difference in the college experience. The students' goal orientation also had a great impact on their persistence. Sources of support included campus resources for veterans, and family, friends and mentors.
\end{abstract}




\section{Introduction}

Since Sept. 11, 2001, over 2 million men and women have served in wars in Iraq and Afghanistan (Serving those who serve: Higher education and America’s veterans, 2008). Most of these service members are between 17 and 25 years of age (Defense Manpower Data Center, 2007). With an increase in the numbers of college-age veterans and improvements in GI Bill benefits, institutions of higher education are experiencing the largest influx of veterans on campus since World War II (Cook \& Kim, 2009).

\section{Statement of Problem}

Helping students persist to graduation is of great concern to institutions of higher education. High rates of student departure and low rates of degree completion can impact a school's finances, reputation, and rankings. A great deal of research has been done on persistence for undergraduate students, including students of color (Cabrera, Nora, Terenzini, Pascarella \& Hagedorn, 1999; Douglas, 1998; Flowers, 2004; Hurtado \& Carter, 1997; Hurtado, Milem, Clayton-Pederson \& Allen, 1999; Jones, 2001; Martinez, 2003; Nora \& Cabrera, 1996; Rendon, Jalomo \& Nora, 2000; Ringgenberg, 1989; Ting \& Robinson, 1998), first-generation students (Dennis, Phinney \& Chuateco, 2005; Ishitani, 2003; Lohfink \& Paulsen, 2005; Pascarella, Pierson, Wolniak \& Terenzini, 2004; Phinney \& Haas, 2003; Richardson \& Skinner, 1992; Thayer, 2000; Velazquez, 1998), and nontraditional students (Bean \& Metzner, 1985; Brown, 2002; Chartrand, 1992; Cini 
\& Fritz, 1996; Cleveland-Innes, 1994; Donaldson \& Graham, 1999; Farabaugh-Dorkins, 1991; Giancola, Munz \& Trares, 2008; Graham \& Gisi, 2000; Kasworm \& Pike, 1994; Metzner \& Bean, 1987; Prather \& Hand, 1986).

Several studies have examined the impact of the first GI Bill on higher education. This included enhancing university systems, revising curriculum, and expanding access for minority and women students (Avery, 1946; Bennett, 1996; Blair, 1999; Clark, 1998; Olson, 1974). Studies of Vietnam-era college students focused on their difficulties with re-entry into a hostile civilian climate, including the college classroom, rather than on persistence per se (Borus, 1975; Faulkner \& McGaw, 1977; Horan, 1991). Studies on current veteran students have focused on campus efforts to provide "veteran-friendly" programs, but have not examined what personal and institutional factors are assisting or impeding veteran students' efforts to persist to degree completion (DiRamio, Ackerman \& Mitchell, 2008; DiRamio \& Jarvis, 2011; Field, Hebel \& Smallwood, 2008; Ford, Northrup \& Wiley, 2009; Lokken, Pfeffer, McAuley \& Strong, 2009; Rumann \& Hamrick, 2009; Summerlot, Green \& Parker, 2009).

While veteran students have some concerns in common with the larger student body, they also have unique needs. Veteran students may face interruption of their enrollment due to deployment, complex disability issues, financial challenges in navigating the GI Bill, and substantial external obligations to their family, community, and Reserve or Guard. As a result they may need special provisions with regard to campus policies and procedures (DiRamio et al., 2008). It is also unclear whether these 
students have more in common with traditional undergraduates or nontraditional students, or if they comprise a unique group that straddles both populations.

The number of veteran students will continue to grow in the foreseeable future (Cook \& Kim, 2009), yet little research has been done on this population of students (though recent work by DiRamio and Jarvis, 2011, provides a good beginning). It is unknown what factors have an impact on persistence for this group of students. Without knowing more about this population it is not clear whether current practices are sufficient to assist this group of students in their persistence efforts or whether additions or modifications of those efforts are advisable.

\section{Purpose of Study}

The purpose of this exploratory multi-case analysis is to explore the perceptions and needs of military veteran students at the University of Missouri, with the aim of learning more about what factors they perceive to have an impact on their persistence. Of interest in this study are the institutional and personal factors that have been shown to affect student persistence including academic goals and pre-college preparation, the manner and quality of relationships with fellow students and faculty, the manner and quality of involvement in school-related activities (both academic and social), the type and quality of support these students receive from the institution and significant others, and the type and intensity of external commitments. 


\section{Research Questions}

The research questions guiding this study are:

R1: What institutional factors do our undergraduate military veteran students perceive to be enhancing and impeding their persistence at the University of Missouri?

R2: What personal factors do our undergraduate military veteran students perceive to be enhancing and impeding their persistence at the University of Missouri?

\section{Definition of Terms}

Persistence. Student veterans sometimes have a break in their college career due to deployment or other issues beyond their control. For purposes of this study, students who continue to pursue their specific educational goal even in the face of occasional breaks in their enrollment are considered to be persisting.

Veteran student. Students who have served with a branch of the armed forces and who have completed their required service are considered to be veteran students. 


\section{Review of Literature}

\section{Theoretical Framework}

This study used Vincent Tinto’s Student Integration Model (1975, 1987, 1993) and John Bean’s Student Attrition Model (1980, 1981, 1982) as the theoretical lens through which to view factors that have an impact on the persistence of undergraduate military veteran students. Both Tinto and Bean focused their research primarily on traditional undergraduate students (students aged 18 to 24 who are attending four-year residential colleges on a full-time basis). Bean, along with Barbara Metzner, also explored factors affecting the persistence of nontraditional students (Bean \& Metzner, 1985; Metzner \& Bean, 1987). It is unknown whether veteran students have more in common with traditional or nontraditional students, or whether they represent a hybrid of both groups. As such, literature on nontraditional students is of value in the present study.

\section{Traditional students.}

Tinto’s Student Integration Model (1975, 1987, 1993) addresses the interactions between individual student attributes and the attributes of the institution. Tinto's focus was on traditional students' transition from their communities of origin to the community of the college. He was especially interested in the quality of social support received by students from peers and faculty within the institution, their feelings of congruence with the institution's academic offerings, and their academic success. When students are able 
to integrate well into the academic and social realms of the institution they are likely to form a bond with the institution. This institutional commitment, along with a commitment to the goal of obtaining a college degree, will lead students to persist to degree completion (Tinto, 1975, 1987, 1993, 1998).

Tinto and others (Astin, 1993, 1999; Pascarella \& Terenzini, 1983, 2005) have approached research on persistence from the perspective of the role institutions can play in supporting student efforts. As such they have urged institutions to develop programs and policies to engage undergraduate students in meaningful social and academic interactions, with the belief that such institutional effort will result in greater persistence. It is not yet understood whether institutional efforts that are aimed at traditional undergraduates are effective with military veteran students. It is also not known whether personal factors (such as maturity gained through military service) contribute towards persistence for these veteran students.

In critical reviews of Tinto’s model, John Braxton and associates (Braxton \& Lee, 2005; Braxton, Sullivan \& Johnson, 1997) affirmed that social integration and commitment to the institution are positively correlated with student persistence. Pascarella and Terenzini (2005) found research evidence to support these conclusions, especially the importance played in persistence decisions by students' institutional commitments.

In their own research, Pascarella and Terenzini (1983) found that the quality of students' social and academic interactions with the college environment had a greater impact on their persistence decisions than their pre-college characteristics. They also 
found that student involvement of all sorts (which they considered similar to Tinto's “integration”) is related to persistence (Pascarella \& Terenzini, 2005). Pascarella and Terenzini (1983) found that, for female students, social integration had a greater bearing on their satisfaction with the college experience, whereas for male students academic integration was more highly valued and had a greater impact.

Bean's Student Attrition Model has a similar focus on student-institution fit. This model had its beginnings in both Tinto's work and in the research on turnover in work organizations by Price (Bean, 1980). In Price's model of workplace turnover, one of the variables is "pay." Because students are not paid for their academic work, Bean replaced this variable with four factors: academic integration (as measured by university GPA), student development, institutional quality, and perceived practical value of the education received (Bean, 1980). Bean also developed the concept of "intent to leave" as a substitute for Tinto’s “institutional commitment.” In Tinto's model, integration into the social fabric of the university leads to commitment to the institution, and thus a greater likelihood for retention and persistence. Bean's belief is that students may feel committed to the institution and yet still plan to leave. Bean contended that by identifying students' intentions regarding departure, institutions can intervene prior to students dropping out.

In his research on traditional undergraduate students, Bean found that intent to leave and university GPA were the best predictors of attrition, followed by students' perception of the practical value of their education for future employment (a variable that supports goal commitment) (Bean, 1981, 1982). 


\section{First-generation and minority students.}

Early research on retention and persistence focused on the experiences of students from the dominant culture (predominantly white, middle-class students from families with a college-going tradition). A substantial body of research has since emerged on underrepresented populations including minority and “first-generation” students (students whose parents do not hold a college degree). Some veteran students fall into these categories.

Students from these groups may face obstacles to their success in college including inadequate academic preparation, inadequate financial support, lack of college and professional role models, lack of family and social supports, and a lack of intergenerational knowledge and experience regarding college with which to help them understand the college bureaucracy and other norms (including academic expectations) (Dennis et al., 2005; Ishitani, 2003; Jones, 2001; Lohfink \& Paulsen, 2005; Pascarella et al., 2004; Phinney \& Haas, 2003; Richardson \& Skinner, 1992; Thayer, 2000). As such, these students are at a greater risk for attrition, especially within the first year (Ishitani, 2003; Jones, 2001; Thayer, 2000).

As with other students, minority and first-generation students benefit from academic and social integration (Hurtado et al., 1999; Ishitani, 2003; Jones, 2001; Lohfink \& Paulsen, 2005; Richardson \& Skinner, 1992; Thayer, 2000). Supportive networks composed of faculty, staff, and student peers (especially with those from a similar background) provide a bridge from the student's own culture to the larger culture 
of the university, thereby helping ease the transition to college life (Richardson \& Skinner, 1992; Velasquez, 1998). Such support increases the dissemination of important information about the college environment and increases students' sense of institutional fit and support (Dennis et al., 2005; Richardson \& Skinner, 1992; Thayer, 2000).

Peer support has been shown to be especially important for college students from underrepresented populations, especially first-generation students. Peers can provide knowledge of the system that parents cannot offer. They can explain policies, help understand and locate campus resources, help with class selection, and otherwise assist in navigating the college or university system. Students report that emotional support from family is important, but it is no substitute for the instrumental support provided by peers (Dennis et al., 2005; Douglas, 1998; Pascarella et al., 2004;).

\section{Nontraditional students.}

There is also a growing body of literature on persistence for nontraditional students. Nontraditional students are generally defined as having at least one of the following characteristics: older than 24, not living on campus, and attending school parttime (Bean \& Metzner, 1985; Chartrand, 1992; Cini \& Fritz, 1996). The population of nontraditional students is increasing on college campuses (Brown, 2002; Donaldson \& Graham, 1999; Giancola et al., 2008). Some have speculated that military veteran students may be more accurately characterized as a subpopulation of nontraditional learners (Avery, 1946; Bennett, 1996; DiRamio \& Jarvis, 2011; Olson, 1974; Summerlot et al., 2009). 
For traditional students, college is both an educational and a social experience. These students are immersed full time in the college experience and are likely to participate in both curricular and co-curricular activities. For nontraditional students the focus is on academic pursuits. Thus, the utility of the courses, certificates, or degrees available is of primary interest (Bean \& Metzner, 1985; Brown, 2002; Cini \& Fritz, 1996). These students often seek specific education or training in response to an employment situation (demand for new skills, layoff from a job) or so they may improve their overall employment opportunities.

Nontraditional students are likely to live off campus. Thus their locus of socialization typically will be their family, community, and work or volunteer efforts. School is just one of many places they are spending their time and energy. They are unlikely to have time to participate in co-curricular activities and may not find any interest in such pursuits (Bean \& Metzner, 1985; Brown, 2002; Chartrand, 1992; Cini \& Fritz, 1996).

Research on nontraditional students has revealed that they are not a homogeneous group. A large percentage of these students are female. Many are members of racial minority groups, may be married and/or have dependent children, may be heads of households, may be working full or part time, and may be first-generation college students (Brown, 2002; Cini \& Fritz, 1996; Donaldson \& Graham, 1999; Fairchild, 2003; Giancola et al., 2008; Kasworm \& Pike, 1994; Kilgore \& Rice, 2003; Prather \& Hand, 1986). 
With these characteristics in mind, it is not surprising to discover the variety of obstacles nontraditional students face in completing their education. These may include a lack of financial support, lack of affordable childcare, lack of support from significant others, working full time, lack of knowledge about and access to campus resources, inadequate academic preparation and study skills, lack of confidence, and outside time commitments to family, work and community (Brown, 2002; Fairchild, 2003; Giancola et al., 2008; Prather \& Hand, 1986).

Researchers have suggested several useful institutional responses to the needs of nontraditional students. These include tailoring support services to adult students, either through modifying existing services (making more available online, after hours, and/or on weekends) or creating new ones (FYE and orientation workshops geared toward this population); and to train support and advising staff to the unique needs of adult/nontraditional students including workplace and family issues (Brown, 2002; Giancola et al., 2008; Rice, 2003; Kilgore, 2003).

Bean and Metzner explored the usefulness of the Bean model with nontraditional students (Bean \& Metzner 1985; Metzner \& Bean, 1987). As with traditional undergraduates, an important variable in attrition of nontraditional students is poor academic integration (measured by Bean as GPA). However, goal commitment also played a significant role. Nontraditional students with poor academic abilities and performance and a low level of commitment to the overall educational process were found to be the most likely to depart (Metzner \& Bean, 1987). 
Considering the external obligations (work, family, community activities) that nontraditional students often have, Metzner and Bean had predicted there would be a direct relationship between environmental factors and dropout behavior for these students. That prediction was not supported. Environmental variables did not directly affect dropout, but three of the variables (finances, outside encouragement, and opportunity to transfer) did have significant effects on intent to leave, and thus an indirect effect on dropout (Metzner \& Bean, 1987). As predicted, the social integration variables had little to no effect on dropout.

\section{Research on nontraditional students using Bean and Metzner model.}

As the number of nontraditional students enrolling in college has increased, research on this population has also grown. The majority of research on adult or nontraditional students focuses on either adult basic education or community college students. There is a limited body of research on nontraditional students at four-year residence-oriented institutions. Much of this research has tested the model proposed by Bean and Metzner (1985), and has continued to use their definition of the nontraditional student in terms of age, residence and enrollment status. This research has shown mixed results.

Chartrand (1992) tested a modified version of the Bean and Metzner model. Her findings had some similarity to those of Metzner and Bean (1987) in that academic variables and environmental variables had a direct effect on institutional commitment and reduction in psychological stress, and thus an indirect effect on attrition. The impact of social integration was unclear in this study. 
Farabaugh-Dorkins (1991) also tested a modified version of the Bean and Metzner model. Like the Metzner and Bean study (1987), this study found both GPA and intent to leave to be the strongest predictors of attrition. While Metzner and Bean also found hours of enrollment and study skills to be important predictors of dropout behavior, this study did not corroborate that finding.

In a similar study Prather and Hand (1986) found that academic integration (as measured by GPA) was the best predictor of persistence, with intention also being a significant variable, though patterns of persistence did vary across gender and minority status.

These studies found little importance for social integration (as conceptualized for traditional students) as a variable for nontraditional students. This may have something to do with how it is measured or defined. Several researchers have determined that the interactions nontraditional students have in class or in academically related activities such as group projects or tutoring sessions are frequently their only significant interactions with classmates and faculty, and serve the purpose of both academic and social integration. Because nontraditional students typically have greater ties to and support from the non-school community, this level of campus integration seems to be satisfactory overall (Giancola et al., 2008; Graham \& Gisi, 2000; Kasworm \& Pike, 1994; Lundberg, 2003).

\section{Tinto and Bean as applied to veteran students.}

Tinto's Student Integration Model focused on traditional undergraduate students (students under 24 years of age who enter college directly after high school, live on 
campus, and attend full time). Bean’s Student Attrition Model also focused on traditional undergraduates, but his work with Metzner expanded that exploration to nontraditional students.

For traditional undergraduates, factors that influence persistence include social integration (through on-campus activities with peers) and academic integration (through developing relationships with faculty and peers that focus on academic pursuits). For nontraditional students, academic integration (through relationships with peers and faculty developed in class and in outside class-related activities) and the ability to balance environmental demands are most important. For both groups, academic success (measured as GPA) and a sense of fit (desired course offerings, perceived value of education, rewarding relationships on campus) lead to an increase in both institutional commitment and goal commitment, and thus a greater intent to persist (Cabrera, Castaneda, Nora, \& Hengstler, 1992; Cabrera, Nora, \& Castaneda, 1993).

While military veteran students often attend full time, they are unlikely to live on campus and typically do not enter college directly after high school. It is unclear how their needs compare to their traditional and nontraditional peers, or what issues and concerns are likely to be important for this population.

\section{Military veterans as students.}

\section{Support from the GI Bill.}

One difference between military veteran students and other students on campus is that the former group has the support of the GI Bill. The original GI Bill (The Servicemen's Readjustment Act of 1944) was initiated as a means to help veterans enroll 
in college, and thus to provide a worthwhile activity for veterans returning from World War II. No one wanted to repeat the general unrest created by unemployed veterans who returned home from WWI (Bennett, 1996; Olson, 1974). The GI Bill provided benefits for up to 10 years from the date of discharge. The costs of tuition, fees, and books for veterans were paid directly to colleges and universities by the federal government (Bennett, 1996; Olson, 1974). Veterans also received a housing allowance. The program proved to be so popular that it was renewed for veterans of the Korean War, Vietnam War, and for military service members who served during times when there were no active conflicts (GI Bill Turns 62, 2006).

However, whereas the Veterans Administration made direct payments to colleges for WWII-era veterans, the process changed with Korean War veterans. A flat fee of \$110 was paid directly to veterans each month for school- and housing-related expenses. This was not enough to pay for costs and many veterans had to hold part-time jobs while receiving GI Bill benefits (GI Bill Turns 62, 2006).

Benefits continued to lag behind costs and the gap widened during the Vietnam era, though those veterans encountered additional hardships. The Vietnam War was unpopular. It was also the first conflict to be widely covered in gritty detail by the national broadcast media. Unlike veterans from World War II, Vietnam-era veterans were vilified upon their return home. Many returned with Post-Traumatic Stress Disorder (PTSD), addictions, or other mental and emotional issues that made re-entry to the civilian world very difficult (Borus, 1975; Faulkner \& McGaw, 1977; Horan, 1991). This meant they were not able to begin college immediately upon their return. For many 
veterans, their GI Bill benefits expired before they were ready to enroll. The veterans who did enroll encountered classmates and professors who were vocal in their opposition to the war, and by association, the veterans from that conflict (Borus, 1975; Faulkner \& McGaw, 1977; Horan, 1991).

In 1985 Congress sought to expand and improve GI Bill benefits and streamline the process for veterans with the Montgomery GI Bill. However it still did not keep pace with actual college costs (GI Bill Turns 62, 2006). In 2008, the GI Bill was again modified. The current iteration of these benefits - the Post-9/11 GI Bill - is very popular with veterans. The benefits are greater (tuition and fees are covered at any school the veteran chooses, no matter the cost) and the allowance for living expenses is tied to the local cost of living. Additionally, veterans now have 15 years in which to use their GI Bill benefits, as opposed to the 10-year limit with previous bills (GI Bill Turns 62, 2006).

\section{Comparison with traditional and nontraditional students.}

While access to the GI Bill is a notable difference between veteran students and others, it is also important to note the characteristics these students have in common with both traditional and non-traditional students. Like traditional students, military veteran students often attend college full time. They also are typically close in age to traditional students. Like nontraditional students they are unlikely to live on campus and typically do not enter college directly after high school.

Veterans are eligible for full benefits under the GI Bill after completing a total of 36 months active duty military service or service in the Reserves (Department of Veterans Affairs, n.d.). As a result, many student veterans are around 21 years of age 
upon enrolling in college (assuming the individual enlisted at age 18). However in the current long-term conflicts in both Iraq and Afghanistan, many of these service members are experiencing multiple deployments or are extending their enlistment. Additionally, with the recent "stop loss" provisions in the military, some enlisted personnel are being required to stay in status longer than they had anticipated. As a result, some student veterans are older (aged 24-30) when they are discharged, and thus when they enroll in college.

The intensity and complexity of military training and service means that veteran students are generally more mature and focused than the traditional college student who is fresh from high school. Thus, while student veterans on campus may be near the age of traditional college students, their broader life experience places them ahead of their peers in terms of maturity and perspective. In these respects, military veteran students may be more accurately characterized as a subpopulation of adult, nontraditional learners (Avery, 1946; Bennett, 1996; DiRamio \& Jarvis, 2011; Olson, 1974; Summerlot et al., 2009). Military veteran students are also more likely to be married or divorced and are more likely to have dependent children (Department of Defense, 2009). In addition to family obligations, veteran students also have commitments outside of the campus, including employment, community activities, and obligations to the Reserve or Guard (DiRamio et al., 2008).

\section{Campus atmosphere and programmatic interventions.}

Recent research has identified specific issues of concern to student veterans in the areas of campus atmosphere, policies, and services. "Campus atmosphere” includes the 
overall atmosphere for veterans as well as issues of social and academic integration. Veteran students choose institutions of higher learning based on affordability, convenience, proximity to family, friends or military base, and available training (e.g., vocational training vs. liberal arts) (Field et al., 2008). Campuses that are popular with veterans are known for having flexible policies, friendly and understanding staff, and a demonstrated effort by faculty and staff to work with veterans and to take them seriously as students (Cook \& Kim, 2009). Information on whether an institution is veteran friendly will spread quickly through word of mouth among the veteran population (Cook \& Kim, 2009; Field et al., 2008). Veterans may also use resources such as the Military Friendly Schools list (http://www.militaryfriendlyschools.com/).

Veteran students cite institutional and community support as being a primary concern. Like minority students, veteran students benefit from opportunities to engage with "similar others" in campus-sanctioned and supported groups and activities, and at designated facilities (Douglas, 1998; Summerlot et al., 2009). Peer support is especially important, with "peer” defined as both fellow students and fellow veterans (which could include faculty and staff) (DiRamio et al., 2008; Ford et al., 2009; Lokken et al., 2009; Rumann \& Hamrick, 2009).

Flexible policies governing enrollment and withdrawal as well as specific fee payment and financial aid policies are important for veterans. Services include advising and financial aid, as well as a greater understanding of veterans' needs within the counseling, student health, and disability services offices (Toolkit for Veteran Friendly Institutions, n.d.). Student veterans may need assistance in transferring academic credit 
earned while on active duty. When considering a degree program, veterans need to know quickly and accurately if their prior coursework will transfer and what additional credits they will need to earn in order to obtain their degree. Institutions can help veteran students by publishing information in a transparent and easy-to-find manner regarding the campus policies regarding transfer credit for military experience (Cook \& Kim, 2009).

Veteran students repeatedly state the importance of having knowledgeable people in the student services area that can provide information and resources to help them navigate the bureaucratic hurdles inherent in both the university and government systems. Areas on campus where it is especially crucial to have staff members who are knowledgeable in veteran services include advising, financial aid, counseling, student health, and disability services, (Ackerman, DiRamio, \& Mitchell, 2009; Bauman, 2009; Cook \& Kim, 2009; DiRamio et al., 2008). Veterans especially need help sorting through the GI Bill and other financial aid options. Having expert personnel on campus is especially important because once these veterans leave the military they no longer have ready access to base personnel who can help them navigate these issues (Cook \& Kim, 2009).

Other programmatic interventions that can be helpful to veteran students include veteran-specific advising, tutoring, and campus orientations. FYE seminars geared towards veterans provide opportunity for guidance on academic matters, introduce veterans to each other, and provide a safe place for veteran students to address concerns or complaints among understanding peers (Summerlot et al., 2009). 


\section{Brief Profile of University of Missouri}

The University of Missouri in Columbia, founded in 1839, is the flagship campus for the four-campus university system. Also known as MU or Mizzou, this land-grant university was the first public university west of the Mississippi. Enrollment averages 35,000 students (27,000 undergraduate) who come from all 50 states and 120 countries. Popular majors include journalism, math, engineering, information technology, health, and other science fields. Freshman students are required to live on campus. MU helped pioneer the use of learning communities and freshman interest groups. The campus has an ROTC program. MU is one of five universities in the nation with all three professional schools on campus (Law, Medicine and Veterinary Medicine) as well as a nuclear research reactor (About Mizzou, n.d.).

During the fall semester, 2012, about 1,600 first-generation first-time-college students enrolled at the university (Enrollment Summary, Fall 2012). African-American students made up eight percent of the total undergraduate student body; Hispanic students, 2.8\%; Asian students, 2.3\%; students who identified as multi-race or -ethnicity, 1.9\%; and American Indian/Alaskan Native students, .3\% (Enrollment Summary, Fall 2012).

Columbia, Missouri, population about 100,000 , is a quintessential college town located in the heart of the state. Nearby military bases include Ft. Leonard Wood and Whiteman Air Force Base, and Ft. Leavenworth (in Kansas). As of fall semester, 2012, there were 526 undergraduate military veterans enrolled on the MU campus (Enrollment Summary, Fall 2012). 


\section{Efforts by the University to Become a Veteran-Friendly Campus}

The University of Missouri has taken steps to become a "veteran friendly" campus. In August, 2007, the university’s chancellor appointed a task force composed of faculty, staff, and veteran students to examine ways to make the University of Missouri (MU) more “veteran-friendly”. When the report of the task force was submitted, the chancellor gave approval to the entire set of recommendations and asked that they be implemented "consistent with the resources available” (Report of the Chancellor's Task Force for a Veteran-Friendly Campus, 2009, p. 36).

Resources associated with this effort that have been utilized by subjects in this study include the Mizzou Student Veterans Association (MSVA, established 2006), the Veterans Resource Center (established October, 2008), and a veterans-only freshman experience class (SSC 1150, Learning Strategies, first offered in fall semester, 2009). 


\section{Methodology}

\section{Sample}

Participants for this study were selected through a combination of purposive and snowball sampling procedures. Purposive sampling was appropriate in this study as the goal was to carefully select research participants who would likely provide rich insight into the questions at hand (Creswell, 2009; Merriam, 1998). The participant pool for this study was limited to undergraduate veteran students on the MU campus who are veterans of the current conflicts in Iraq and Afghanistan, who did not attend college prior to enlisting in the service, and who have since completed at least one semester at the University of Missouri. The participant pool was not limited with regard to gender, age, race, ethnicity, year in school, or branch of service.

Participants included two women and two men who ranged in age from 24 to 51. Two participants identified as Caucasian. One identified as mixed-race and one as multiethnic. Three of these students are first-generation college and identify as coming from families of low socioeconomic status. Two participants are veterans of the Navy; one served for six years and the other is retired Navy. One is has been serving in the Army National Guard since 2007. The forth served in the Air Force for 12 years and is now with the Air National Guard. None of these students were involved in combat missions. Three students are attending school on campus full-time. The fourth works full-time and 
attends classes part-time through an evening online program. The two female students are divorced and have children. The two males have never been married and are not parents. Table 1 provides demographic information on these four students.

Figure 1: Demographic Matrix of Participants

\begin{tabular}{|l|l|l|l|l|l|l|l|l|l|l|}
\hline Name & Age & Ethnicity & Gender & $\begin{array}{l}\text { Marital } \\
\text { Status }\end{array}$ & Children & $\begin{array}{l}\text { Branch of } \\
\text { Service }\end{array}$ & $\begin{array}{l}\text { Years in } \\
\text { military }\end{array}$ & $\begin{array}{l}\text { Deployed } \\
\text { overseas? }\end{array}$ & $\begin{array}{l}\text { Combat } \\
\text { experience }\end{array}$ & $\begin{array}{l}\text { Reason for } \\
\text { enlisting }\end{array}$ \\
\hline Amy & 32 & Caucasian & Female & Divorced & $\begin{array}{l}\text { Daughter, } \\
\text { age 5 }\end{array}$ & $\begin{array}{l}\text { Air Force; } \\
\text { Air National } \\
\text { Guard }\end{array}$ & $\begin{array}{l}12 \text { in Air } \\
\text { Force; six } \\
\text { months in } \\
\text { Guard }\end{array}$ & Yes & None & Pay for school \\
\hline Andrew & 24 & $\begin{array}{l}\text { Mixed } \\
\text { race \& } \\
\text { ethnicity }\end{array}$ & Male & Single & None & $\begin{array}{l}\text { Army } \\
\text { National } \\
\text { Guard } \\
\text { had seven } \\
\text { years of } \\
\text { service as of } \\
\text { Nov. 2012 }\end{array}$ & $\begin{array}{l}20 \text { years - } \\
\text { retired } \\
\text { military }\end{array}$ & Yes & None & $\begin{array}{l}\text { See the world } \\
\text { and then go to } \\
\text { college }\end{array}$ \\
\hline Lillian & 51 & $\begin{array}{l}\text { Mixed } \\
\text { ethnicity }\end{array}$ & Female & Divorced & $\begin{array}{l}\text { Daughter, } \\
\text { age 28; } \\
\text { son, age 26 }\end{array}$ & Navy & None & Six for school \\
\hline Scott & 26 & Caucasian & Male & Single & None & Navy & No & None & $\begin{array}{l}\text { Pay for school; } \\
\text { see the world; } \\
\text { find a career, } \\
\text { not a job }\end{array}$ \\
\hline
\end{tabular}

\section{Recruitment}

Efforts to contact participants were made through several means. A notice of the research study was sent via mass campus email to faculty, staff and students. Emails that included a printable recruitment flyer were sent to the undergraduate advisors group, as well as other targeted faculty and staff, requesting they pass word of the study to veteran students with whom they had contact. This effort was made three times during the school year and several advisors indicated they had contacted veteran students. Flyers were also distributed on campus bulletin boards.

The director of the campus Veterans Center had been an enthusiastic supporter of this research. Despite sending several emails to the director and student advisor at the 
Veterans Center, it was not until I made a personal visit in November to the Center that those staff members sent the information to their veteran listserv.

I also contacted the president of the Mizzou Student Veterans Association (MSVA) to seek her assistance in recruiting participants. However, she became alarmed in my interest and became very protective of the MSVA members. Several times I provided an explanation of the research, contact information for my advisor, and information about how to verify the study through the Institutional Review Board, but she refused to discuss the situation and would not meet with me. It is unclear what impact this situation had on recruitment efforts.

Assistance came from a professor on campus that is a decorated veteran and is active with MSVA, but his support did not result in participants.

As participants were interviewed, I encouraged them to share information about my study with their friends. This "snowball” approach can be useful in gathering additional participants who, because of their referral by another individual familiar with the study, are likely to provide important perspectives (Creswell, 2009; Merriam, 1998). However, these efforts did not result in additional participants.

Because so little is known about this population, it was unclear what themes might emerge and whether a pattern of data saturation would develop in this research. Rather than interviewing participants until data saturation occurred, I planned to conduct five to 10 interviews. Even though only four participants were interviewed, I believe this study can still contribute to our understanding of this group of students. 


\section{Data Collection}

Once a veteran student indicated interest in this research, a pre-screening survey was sent via email. The survey asked for demographic information as well as brief information about his or her service history (see Appendix A). The survey was returned to me via email, and then an in-person interview was scheduled.

Along with the pre-screening survey, prospective participants received a consent form that explained the purpose of the study, information on protection of privacy, and contact information for both me and my committee chair (see Appendix B). A printed copy of this consent form was also offered at the start of each interview. Oral explanation of the purpose of the study and confirmation of privacy was made at the outset of each interview, and protection of privacy was reiterated at the end.

In order to allow participants to express ideas and experiences in an open and flexible manner I conducted semi-structured interviews (Creswell, 2009; Merriam, 1998). The same general, open-ended questions were asked of all participants. Follow-up questions and prompts were tailored to each individual's responses. Each session lasted from 75 to 90 minutes.

Interview questions focused on the nature of individuals’ perceptions and experiences as students. Concepts of personal and institutional factors that were supporting or impeding progress towards the degree were discussed. This institution has made significant efforts since 2009 to become “veteran friendly.” While this research does not focus on the "veteran friendly" programs and policies on the campus, failure of a veteran student to mention these services would be significant. Because I wanted to 
refrain from leading the interviews in the direction of specific campus services, questions that might prompt subjects to discuss these services were left to the very end.

It was not germane to my research to ask about specific events or experiences related to veteran students' combat missions. However, I anticipated the possibility that during the course of the interview some participants might bring up painful experiences related to combat duty. I was prepared to end an interview, and even offer assistance as appropriate, but this situation did not arise.

Interviews were held in the conference room in my office suite, which is both private and ADA-compliant. Participants were offered this location but were also told they could choose a different option if they preferred. All participants chose the conference room.

Audio recordings were made of all interviews. Participants were asked if they had any objections to being recorded; none did. Verbatim transcriptions of each interview were made.

In order to protect privacy, each participant was assigned an identifying number. The identifying number is noted on the interview transcripts, and on a spreadsheet that includes the participant's name. Participants' identifying information was kept in a separate file from their interview transcript. Pseudonyms have been used for research participants and unique identifying features have been disguised.

In recognition of the time and energy it takes for individuals to participate in such interviews, and of the value of the information they provided, subjects were entered into a 
pool for a chance to win one of five gift cards from the University Bookstore. Because there were only four participants, each interviewee received a gift card.

\section{Analysis}

Because so little is known about undergraduate military veteran students, this research was conducted as an exploratory multiple-case study. Case study analysis involves the researcher examining recurring themes and patterns that emerge organically from the data, and building a holistic sense of the case. The goal is for the data to lead to discovery of patterns, rather than to impose patterns on the data (Creswell, 2009; Merriam, 1998; Stake, 1995).

This exploratory study used a multiple-case study design to examine the experiences and perceptions of veteran students. The context in this study is defined as the University of Missouri's campus in Columbia (MU). The case is defined individual undergraduate military veteran students at MU.

Case studies are specific instances, bound by time and activity. Such studies are appropriate when one seeks to gain greater understanding of an individual, group, organization or event in a holistic manner, within context of the particular time and place (Creswell, 2009; Merriam, 1998; Stake, 1995; Yin, 2009). The present case study is bounded by the specific student population (undergraduate military veteran students), the institution (the Columbia campus of the University of Missouri system), and the time frame (the study took place during the 2012-13 school year).

For this study I used the "constant comparison” method of data analysis whereby each piece of data is systematically compared against all other data in the study in order 
to discern the patterns that exist within the case (Creswell, 2009; Merriam, 1998; Stake, 1995). Data analyzed in this study included the interviews conducted with each participant. I read each interview several times, highlighting significant concepts and phrases as they appeared (e.g., mention of campus services, rusty academic skills). These concepts were grouped into larger categories based on common characteristics. Finally the categories were grouped into larger themes.

Initial themes I anticipated encountering include those of engagement with faculty and fellow students; academic preparation and goals; the interplay among subjects’ academic and external commitments; and participants’ experiences on campus as a veteran of the armed services (e.g., reactions from members of the campus, experiences with obtaining GI Bill benefits). As the research progressed additional themes emerged. Most surprising was the feeling of all four participants that pursuing a college education after having time away from the classroom was much harder than they anticipated. Each student expressed surprise and dismay at their "rusty" academic skills, the changes in technology, and how much time and effort was needed for their school work. Surprising, too, were the factors that seemed most germane to these students’ persistence, namely their motivation for obtaining a college degree and the sheer diligence and determination each cited in keeping them in school. All four students noted the personal growth and maturity they gained in the armed services, as well as development of strong work habits.

Finally, all of the categories were grouped under five main themes: Academic Challenges, Struggle to Balance, Transition to Civilian Life, Support, and Goal Orientation. 
In order to reduce researcher bias and provide rigorous analysis of the data, I asked a former graduate student of the School of Journalism, Emilie Stigliani, to review all four transcripts and identify concepts and themes. This student had been identified by a faculty member who teaches qualitative research as an expert in the constant comparison method. Transcripts (with pseudonyms) were emailed to Emilie, along with the research questions. Emilie read through and coded the transcripts first without reading the research questions. This allowed her to interpret the data without pre-conceived bias. She then read through a second time with the research questions in mind. Emilie then returned the transcripts to me with both sets of comments included, and color-coded to distinguish between them. Our perceptions of the data seemed nearly identical, though her labels differed somewhat from mine. This led me to re-read each transcript to determine whether there were significant discrepancies in our analysis, or if we simply used different language to describe the same essential issues. While our perceptions were largely the same, this review resulted in development of the category of Struggle to Balance. 


\section{Results}

The cases in this multi-case analysis are comprised of the four veterans who were interviewed. In this section each veteran is profiled. The four cases are then compared in a cross-case analysis.

\section{Veteran Profiles}

\section{Amy: School is her mission.}

Amy is from a small town in mid-Missouri. She was a good student who came from a very "poor” family. The military had never been part of the plan for her, but when faced with how to pay for school her plans changed. She enlisted in the Air Force right after high school graduation.

I think everyone was really shocked. Because I was toward the top of my class and everyone was really surprised that I chose to go with the military. I think everyone assumed that I would go to college and... just be normal, I guess? But, they weren't gonna pay for it. Who was gonna pay for it? So I chose the military and I credit it as being one of the best decisions I ever made.

Seeing the world was also an exciting prospect for Amy, and she knew she could take college classes while in the Air Force.

And also, growing up in such a small town I just always had this desire to go see what was out there. So I joined the military. And I started school right after I got into the military, once I got to my first base I was going to school at night and on the weekends and it just takes so long when you're doing one class at a time.

After 12 years in the military Amy had been married and divorced, had a daughter, and still did not have a college degree. She knew that if she wanted to "make it 
anywhere in life" she would need to finish her education. She decided to leave the Air

Force and enroll at the university.

So I thought, the reason I joined the military was, I couldn't afford to go to college. So I wanted to pay for it with the GI Bill. And after I spent almost 12 years in the military I'm thinking, I still don't have my degree, and that was my plan. So you know what, I'm just gonna go for it.

Amy enrolled at the university in August, 2012. She was immediately struck by the difficulty of college, which was greater than she had anticipated. The amount of reading, new technology, and classes in statistics and Spanish combined to create a “tough” experience. "So yeah, I never really thought about how tough it was gonna be, honestly. I mean, I did some tough things in the military and I didn’t think this was gonna be a big deal. So it’s an eye-opener.” The day that Amy was interviewed was an especially hard day.

And I got a D today on my Spanish test. And I got an A in Spanish [last semester] and I worked really hard because it's been like, 14 years since I took Spanish. And I don't know what happened but it was not good. So I look kind of crazy, I was, like, crying. I feel... Like, I'm 30 years old, I'm 32 actually, and I'm crying over school, and I feel so silly. Because this is, it's hard. I will tell you that.

Amy is also struggling with her statistics class and believes the gap since high school is partly to blame. “I mean, this is my first math class in I don't... I mean, I took College Algebra probably eight years ago. And I struggled with that because it had been five years since I had been in high school.”

She also wonders if her high school could have prepared her better in both math and foreign language. "I mean, a lot of these kids took statistics in high school. I don’t think 14 years ago they had statistics in high school. Maybe they did, but definitely not in 
[my] high school. I mean, I took up through Algebra II and that was it." "And oh man, if I could go back I would have just taken four years of Spanish in high school but, I didn't know. You know, back then I don't think our counselor was really aware of that.” Amy found it to be difficult to be a returning student in the classroom with students who have not had a break in their academic activity. This contrast has dealt a blow to her confidence. She sometimes feels "old” and "dumb.”

And then the fact that I've been out of full-time school for so long. So I don't remember a lot of the stuff that the kids... that they remember from last year and they just graduated. And I was a good student in high school. I had probably like a 3.7-8. I'm not dumb by any means. But sometimes I feel like I am.”

Amy graduated high school in 1999 and computer technology has changed substantially since that time. She was dismayed to learn that one of her classes would require her to create a video in iMovie.

And I'm like, I don't know how to use that. What do you mean? So, and no one else in the class seemed to have a problem with it. Because I'm thinking okay, well they're all in this technology age. And, I mean I'm not old, but we just didn't use this stuff. And I've been in the back of an airplane cooking food for, you know, dignitaries. I certainly wasn't playing on iMovie. So that kind of knowledge gap I'm trying to fill in and trying to play catch-up.”

Amy wonders sometimes if she is in over her head, but she is also proud to be at the university and proud of her accomplishments.

So, I mean, I feel very, I'm proud to be at Mizzou. I mean, I'm very proud to be here, but sometimes I think, man, did I bite off a little bit more than I was ready for? More than I can chew. So every day it's like, I have to remind myself, I can do this, and I'm here for a reason. I'm hangin' in there. 
Amy is a single parent. Her daughter is five years old. One reason she returned home to attend the university was that she could live with her mother in a nearby small town. She hoped this would provide some stability as well as assistance with child support. Amy found it to be very hard to juggle the demands of commuting, parenting and school work.

It's far, I mean, it would take me an hour to commute, by the time I got to the shuttle bus and everything. And then I would come to school all day and then I would go home, and I would take care of my daughter for three hours and then I would start my homework, and it's already 8:00.

Amy did her best with this situation during her first semester, but finally contacted her ex-husband and asked him to take temporary custody of their daughter. “But around Thanksgiving I called her dad and I said, you know, I’m either gonna have to drop out of school or you're gonna have to, like, step in and take care of our child while I do this because it’s just, I can’t keep up. So he did, and now she’s with him....”

With her daughter gone, Amy moved to Columbia. Her commute has lessened considerably and she no longer has daily childcare duties. However she struggles with being an absent parent.

...I'm still having a hard time. I'm having a hard time being away from her. I'm like, a guilty mom a little bit. I'm like, I'm doing this for both of us but it feels a little bit selfish. So I'm always questioning, am I doing the right thing? Is she gonna suffer because I'm not there? So, so I have that that I struggle with daily. You know, having, like, that family.

And I miss her a lot, and so even though I'm not taking care of her at night I'm still trying to make time for her on Skype and Facetime and trying to see her and keep that relationship strong. And some nights I'm like, I don't have time to talk to her and I feel really bad. It's just, you know, as moms I think you want to be able to do everything and you just can't, and so I'm just trying to reconcile that with myself. You can only do what you can do and she's gonna be okay. 
Amy credits her 12 years of military experience for helping her to mature and become more confident. She feels like she grew up while in the military, "in an environment where, you know, failure is not an option.” She says when she was younger she would have "fallen apart" if she made a plan and it did not work out. In the military she learned how to adapt plans as needed. She became more resilient. "It allowed me to... I was sort of forced to go and just build my own life. I would say my family, like my upbringing wasn't so great. Even though I excelled at academics, if you were to go back and look at my background you would probably wonder why, like, how I did that.”

Amy also credits the military for helping her to become more independent, motivated and persistent. She learned to “not settle” for something she doesn’t want.

So, the military taught me to not, pardon my language, take any bullshit. Like, I'm not gonna just settle for the first answer I get if it's not what I want. Because in the military you just don't do that. And I've kind of been applying that to, like, every part of my life. And it's working out...”

Amy spoke of working 30-hour days, living in a tent in the desert for weeks, and just being exhausted. But the work ethic she gained, along with all of the other personal qualities she developed, make Amy very grateful to have been in the military prior to college.

Like, there was a lot of times that I didn't want to go to work. And I had to work after hours and work late, and I had to work 24-hour days and like crazy things. But when I look back now I don’t ever think about those times. I only think about all the things the Air Force gave me. I get little goose bumps just talking about it...which is funny because I haven't really thought about that for a little while.”

Military service provided Amy with a "perspective of the world" that was different from her small town. She was initially stationed in Oklahoma and Texas, but 
then began a job that required her to travel the globe. Amy contrasts her perspective to that of the students who entered the university right out of high school. "But because they haven't seen what the rest of the world is like it just, I feel like, you know, it's sort of an edge for me. I have a little bit more of an edge with the respect and um, just really knowing how an adult acts. I mean, how grownups act.”

She also believes her perspective as an older student makes her more appreciative of her educational opportunities. She feels like she has more of an investment in her education and is "more thankful for the opportunities than I would have been when I was 18.” Amy gets frustrated by the "immature” behavior of her fellow students - not arriving to class on time, packing up and getting ready to leave while the instructor is still talking, and texting or using Facebook during class. "You know, in class when the instructor is saying, you know he's constantly reminding the students, 'Oh you know, this quiz is, it's due.' And I think that's really nice of him to do, but it's listed in the syllabus. You can't read it?”

Amy also feels frustrated by the seemingly trivial complaints of her fellow classmates, especially complaints about being tired.

[F]or example, in a Spanish class last semester. It started at nine, and the students are showing up and a couple of them are like, "Oh my gosh, I'm so tired.” And I'm thinking, “It's 9 a.m. I have been up since five. I’ve already worked out, fed myself, got myself ready for school, got my daughter ready for school, put her on the bus and drove an hour to be here. Like, why are you tired? I don't get it. Like what do you mean you're tired? 
Amy's has identified public relations as the career path she wishes to follow. But her training in the Air Force was not in this area. Amy has joined the Air National Guard as a way to gain practical work experience.

When she first joined the Air Force, Amy worked as a supply clerk. After four years she took on a special duty assignment as a flight attendant for VIP travel. This required her to fly with dignitaries such as the First Lady and Secretary of State to countries around the world. Her duties included cooking meals for those on board. She enjoyed the glamour of the job, but her professional goal is to work in public relations, not to work as a flight attendant. She identified the Public Affairs division of the Guard as a good opportunity to gain practical experience as well as other benefits.

She began attempting to get on in Public Affairs even before leaving the Air Force but met with resistance from the recruiters who wanted to place her in other areas. Amy put to work all of the qualities she had developed in the Air Force - motivation, perseverance, persistence, and an unwillingness to "settle" for something she did not want. After a year was able to get hired on in that division. "Well, I finally drove over there one day and just walked into the office and I said, 'Listen, I don't know what I need to do but I want this job. And I'm gonna sit right here until you tell me why I cannot have this job.’ And at the end of the day I had the job.”

This choice will provide financial benefits beyond those she receives through the GI Bill. These include a paycheck and additional health care benefits. Amy will have to take a semester off from school however, in order to receive training. For Amy, this break in school is a small price to pay for the benefits she will receive. 
But I think going back was a good thing for me because it gave me, like, you know, just the foot in the door, just to kind of feel the camaraderie every now and then. And not to mention the practical work experience for my resume. So I'm really excited about that. So you know, it adds on an extra semester but it was the right decision.

Amy has mixed feelings about the services offered to veterans at the university. Like Scott and Andrew she participated in the campus's orientation program, Summer Welcome. She appreciated meeting her advisor (with whom she has a strong relationship) and was very happy to learn about services for veterans on campus, including the free tutoring. Amy feels like tutoring is making a big difference for her in both Spanish and Statistics. "The very nice thing about the veterans thing is that I get free tutoring at the Student Success Center, that is huge. Because I wouldn't really be able to afford it.”

Like others, Amy has her GI Bill benefits processed by the Veterans Center, and she appreciates that service. She is grateful for this funding, but noted that the GI Bill does not provide support during breaks from school, which can create a financial strain.

So trying to juggle my finances, and you know, when we were on Spring Break we don't get paid, when we're in school, on the GI Bill. When we're on breaks from school that was five weeks that we did not get a paycheck. So yeah, I did some babysitting and thankfully I saved money. I wouldn't have been able to do it if I wouldn't have planned about seven or eight months in advance that I was gonna do it.

The paycheck Amy receives for her work with the Air Guard helps to bridge those funding gaps.

Amy tried participating in some of the activities sponsored by the Mizzou Student Veterans Association (MSVA) but felt a little out of place. On the two or three occasions that she attended a meeting she found that the group was made up largely of men who had been in the Army. As a female veteran of the Air Force she felt like she did not 
match up with the group. She also acknowledges that she has not had a chance to fully explore this group due to academic pressures. “And I'm so busy I don't get to go to a lot of the veterans meetings and actually mingle with a group of people that may have the same background as me. I just haven’t gotten a chance to because I'm trying to stay afloat right now in classes.”

Amy was disappointed that the MSVA group did not work out. She does not have a close group of friends on campus or in Columbia, but she wishes she did. She listens to classmates who are tapped into the student network and envies that connection. "And so when I hear people talk and, 'Oh my friend took this class and they said this, this, this, and this.' And, um, just all the advice that, like, the students get from each other...Yeah, I feel a little bit isolated from that."

She moved in with a roommate in Columbia in January and is very happy about that decision. But that woman works evenings and is busy with her own boyfriend on the weekends, so Amy has not been able to expand her social circle through her roommate.

People on campus have suggested that Amy might find friends among the graduate student population but she doesn’t know how to make that happen. “Okay, what do you do, just, like, hold up a sign?” Though she is near her home town and old friends, Amy longs for her friends from the Air Force who she perceives as being the people who know her the best. And yet she is so busy, she’s glad at times that her friends are not here.

It's really important to have like the social, just, an outlet. But, honestly, I'm like, thank god that [my] boyfriend lives across the country because I don't have time for you, really. So, and you know, when I miss my friends that are all in Washington, D.C., I think, you know, if I were there I don't know if I'd be doing as well in school as I am. 
Like Scott and Andrew, Amy is a first-generation college student. Amy's mother became pregnant at a young age. Her father has been virtually absent. Amy’s mother has almost no understanding of her experience.

...my mom, you know, she's uneducated herself. She doesn’t really, I don't think she really knows what it took for me to do this and I don't think she understands or grasps just exactly what it is I'm doing and how big it is. But I mean, of course she says "I'm proud of you." She just doesn't know. You know, I mean, I made the Dean’s List, she doesn’t know what that is.

Amy has been pleasantly surprised to find a relationship developing with her grandfather in another town nearby. "And he’s probably the only one that, around here, he calls me to check on me and he keeps telling me, 'You can do it.' And that's really great. We're not, we weren't really that close when I got here. We're getting closer now and I'm really, I'm glad that he's there...”

Without a knowledgeable, involved parent, or nearby significant other, or close group of friends or classmates on campus, Amy finds herself having to provide her own reinforcement. "So you know, not having that, not having someone to, like, kind of provide you with positive reinforcement, yeah, I mean, that sort of is lacking a little bit. But I just keep telling myself, ‘Good job.’”

Amy sometimes wonders if leaving the military to pursue a college degree was the right decision. Her promise to herself to complete this goal is one of the factors that motivate her to continue.

And there are days I wake up and think, "I made $\$ 70,000$ a year. Why did I do this?” That was enough for me. I didn't need any more than that. Like, why did I do this? But, I don't know, it's like a self, like, internal, just desire for me to accomplish this goal that I set for myself a really long time ago. And so that keeps me going. But there are not a lot of other factors that keep me going. Like, I'm by 
myself and this is all I really have. This is my mission, really. And so this is what I'm gonna do.

\section{Andrew: Family first.}

Andrew is from a small town in northern Missouri. He enlisted in the Army National Guard during his junior year of high school. Andrew completed Basic Training during the summer between his junior and senior year. Upon graduating high school he completed his Advanced Individual Training (AIT), during which time he learned a specific skill to be used in the Guard (for Andrew this was welding). His plan was to enroll in college that fall, but when he returned from AIT he was told he would be deploying within a few months, so he deferred his enrollment. Andrew deployed to Kosovo that spring and ultimately enrolled at the university two years after he graduated high school.

Andrew’s reason for enlisting was very straightforward. He wanted a college degree so that he could get a good job and help support his mother and sisters. He enlisted in order to receive the education benefits of the GI Bill. Andrew even used some of his tuition assistance to pay for a handful of dual-credit classes while he was in high school.

I come from a very, very poor family. But...I'm good at standardized testing. And I had very good grades, and I needed a way to pay for college. So the way I figured it, I could join the Guard, pay for school, make money, and then my mom can help my sister go to school. So that was my main goal when I joined up. I did it for the schooling, so I could pay for school. I mean, I'm glad I could help my country, and serve in that way, but this was a means to an end.

Andrew was a good student in high school who enjoyed science. (He participated twice in the statewide Science Olympiad held annually in Columbia.) 
During his junior year his high school chemistry teacher encouraged him to major in engineering. Andrew applied to the science and technical branch of the university, located in the southern part of the state, and was prepared to follow that path. However, upon his return from Kosovo he learned that his father had relocated to Columbia and determined that this campus was a better choice. He laughed that he ended up transferring to the Columbia campus before he had even started college.

Well, my dad got out of prison when I was in my senior year of high school, and then he was living in Kansas City but moved to Columbia. So I decided I wanted to be closer to home. I ended up transferring before I ever got to college I guess, to University of Missouri. I was just going here because it was close to my dad.

Andrew enrolled in the engineering program at the university. He quickly

discovered however, that his math skills were not proficient enough for this area of study.

It was originally engineering but, well, a couple of years not taking math classes and then I took pre-calc and I struggled to get through that. I ended up getting a C. Then I took Calc I and I didn't end up passing. And I retook it and then halfway through I was like, “This is, no, no. I'm done.” Literally all of my other classes were suffering because I was studying so much for my math classes and still not doing well.

Andrew acknowledged that math was not a strong area for him. "I mean, some people are math people. I'm not overly good at it." But he also found that he was struggling to keep up with the pace of the college classroom.

I remember, sitting in pre-calculus and listening, and I remember everything she just taught us, going over in Algebra II [in high school] in a quarter of a semester. That was a class period. And then she started the next lesson during that same class period. I just felt like I was moving slow. I mean, I should be able to do this faster. It's just simple algebra or whatever. I mean, it's coming at you like a deluge, and so much of it. 
Andrew experienced one of the transition struggles that some other bright high school students face when they get to college, namely that they must develop effective study habits. They cannot complete all of their homework in class and must establish study routines and time management practices for their school work. Andrew stated that he had never developed effective study habits - that he never did homework at home while in high school.

For me at any rate, high school was not something that was particularly challenging. I would do my homework in my classes and that kind of thing. I never did homework at home, never, ever. And then you get to college and it's like, “I have three chapters to read by Friday. What?” And that's on top of everything else you have going on in your other classes. It's a heavy work load.

Not only did he have to develop appropriate academic habits, but Andrew was also in class with students who had not had a break in their academic activity. "And then while you're also re-learning how to learn when you have people who, they just left high school, who have always been in school setting, so it’s just continuous for them.” Andrew spoke of this transition to college as taking at least a year. "I mean, first semester is a huge readjustment period and you're trying to work out the kinks that second semester. I mean, sophomore year you're back in the groove a little bit. But that freshman year was tough. It was real tough.”

Andrew also spoke about the challenge of transitioning from a highly structured environment to an environment that is much less structured, more "fluid."

Yeah, in the military it's so structured. "At this time you do this, on this day" and it's generally the same thing every day. Then you come to 
college and you have, "Well, on Fridays I go to class at noon, but on Thursdays I go at whatever time.” So your days are starting at different times. Everything's fluid, everything's moving.

Like Scott, Andrew spoke of no longer having to report to a commander and thus having to be more self-disciplined.

And then again, you don't have that person sitting there like in the Army. 'When I tell you to go do something, I expect you to go do it.' And you'd better do it, or you're in trouble. And then [in college] you're supposed to do something, but you don't want to do it, and you don't have to do it, and then you see the reflection on your GPA at the end of the semester.

Andrew also spoke of the loss of espirit de corps. He said that the military is structured so that people are working as a team; they rely on each other daily. In college, a student's achievement is based on their individual effort. There is not a team relying on that student to perform well.

[Military members are] used to having people rely on them they're used to having to come through for people. Then you get to college and it's all on your own. You're one of 30,000 walking through the campus or whatever, and no one really cares whether or not you pass that class. No one really cares, you're not going to let anyone down, other than yourself and a few people hundreds of miles away, your family, wherever they may be.

This sense of duty to other veterans is one factor (in addition to his problems with math) that led Andrew to switch his major to psychology. Fellow veterans were returning from combat duty and Andrew witnessed their mental and emotional struggles. He also had an interest in psychology based on coping strategies he had developed as a child.

And then at the time, some of my buddies, who I had known through the Guard, some of them were coming back from other deployments and stuff like that. They were going through some really, really rough times. And I've always been good with people and helping other people figure out their problems and stuff like that, and I figured psychology and dealing 
with soldiers.... I mean, I'm a soldier, I already have an inside perspective, which is better than most psychologists will have. I just thought I'd try to help veterans. And also psychology is something I love. I like figuring out how people tick. I had to know how people ticked when I was a little kid because somehow it was necessary. So I had developed some skills, I might as well use 'em.”

Like Scott, Andrew sometimes found his fellow students to be immature. "Oh yeah. They're losing their head over something that's like, 'that's so trivial.' You just want to take 'em by the head and say, ‘what are you doin’?” Andrew was surprised at the differences between him and his fellow students considering he is close in age and appearance to the other undergraduates on campus. He also referenced Billy Madison to illustrate his point.

I'm not that different from the demographic here but still sometimes...I sit there and I'm like, 'You all were in like $7^{\text {th }}$ grade when I was a senior.' It's like from Billy Madison, freakin' 30 years old and in a second grade class. And then I make a reference and they don't understand it and I'm like ahhh, okay, this is what it feels like to get old.

Andrew is still enlisted in the Guard and is an active participant in veterans’ activities on campus. Perhaps for these reasons (and the fact that he has an outgoing personality) he is willing to reveal his status as a veteran. However he is still cautious about when to do so. When the subject of the military comes up in class he sometimes makes the choice to "put my two cents in.” At times professors and classmates have thanked him for his service. Sometimes though, his friends don’t give him that choice and instead reveal his status for him. This can be an uncomfortable experience.

Like you'll go to a party and then someone will be talking about something and one of my buddies will be like, "Yeah! This guy, he was in the Army!!! Yeah!” And then you get the stupid question of "Hey, did you kill anyone?” You get that from everyone. I mean, obviously, the younger they are the more insensitive they are about it. But anymore I just write it 
off. Like, whatever. "Wouldn’t you like to know” or I just say something flippant or you kind of ignore it.

As stated earlier, one impetus for Andrew switching his major to psychology was his interest in helping fellow veterans. Towards this end he is volunteering at Welcome Home, Inc. through the university’s Service Learning Program. Welcome Home is a notfor-profit organization that assists homeless veterans. Andrew is excited and proud about his work there. It is related to his major, allows him to feel helpful and involved, and allows him to put some of his talents to work (networking, problem-solving). Andrew perceives this as an opportunity to learn more about the larger scope of a social service agency.

[But] I wanted to see how the entire system worked. And for veterans, how do they get care. And where they go through and what's their point of contact. You have a homeless person. How are they supposed to get to where they need to go to even take care of this stuff. So I wanted to see that side of it. I wanted to see how they ended up getting to the clinician and stuff like that. I wanted to see the process of them getting to that point.

Andrew quickly discovered a staffing shortage at the organization, as well as a need for better marketing and volunteer coordination. He is working through the Service Learning Program to find more volunteers to help with these needs. For Andrew, this work is important on both a personal and professional level. "I love doing what I'm doing right now. And I want to continue to help. I mean, I'm a veteran. I could see a lot of possibilities where something could have happened and I could have been in a position of 'I haven’t got a place to stay.','

Andrew has taken full advantage of services on campus that assist veterans. Like Scott, Andrew has worked through the Veterans Center to coordinate his GI Bill benefits. 
At first he was unaware that the campus had such an office. When he asked at the

Registrar's office about coordinating GI Bill benefits a staff member told him about the

\section{Veterans Center.}

And they pointed me in that direction, and they showed me everything and I was like, “Ah, you're the guys who I want to go through.” And so I went through them and they basically pointed me wherever I needed to go. And they went, "Okay, you need to go here.” And I'm like, “Cool beans, tell me what I need to do.” That's literally how I did almost everything was through contact with them.

During Andrew's freshman year the campus offered a veterans-only section of

Learning Strategies, which is similar to a first-year experience course. Andrew enrolled in this course in his first semester and found it to be very helpful, especially with identification of useful campus resources. He also acknowledged that he learned important academic skills through this course, though he did not fully appreciate or implement these skills until after a couple of semesters in college.

And like a lot of stuff you just say, "ah, whatever." And then two years later you're like "they were right.” Because you think you know everything. Especially me, I think I know everything. So I’m like, “yeah, they were right, that's a good idea." I mean, it helped a lot. I mean, it put me in reference with a lot of point of contacts I use now, like the Student Success Center. But it's like, you learned things that were gonna help you here, and you met people who were gonna help you here.

Andrew is also active with the student veterans group on campus, MSVA. He has attended some of the meetings and has participated in the group's activities including an annual summer float trip and an annual lunchtime cookout on the campus called Operation Free Lunch. He finds MSVA to be a positive experience and it is one of several social outlets he has on campus. He also participates in the Black Culture Center, goes to the campus gym, and hangs out in the student union. Andrew lives with fellow 
students he met during his freshman year, and he also has a tight group of friends that he likens to his squad in the Guard. "I’ve got four or five ...people and that's my group. We're with each other almost every day and stuff like that. So you kind of get that familiar sense of like, 'Hey, they’re here, they've got my back.’”

Having a tight group of friends who "have his back" is important to Andrew because he does not perceive his family to be a source of this sort of support. "I don’t rely on anyone in my family in that way because they're generally relying on me like that. So I've never really asked someone in my family to kind of prop me up like that.”

Andrew is the ninth of ten children. His family is composed of several halfsibings. His parents divorced when he was young and he chose to live with his father. His father was in and out of jail so Andrew frequently lived with his grandmother and other members of his father's family. Andrew's father finally went to prison "for a good long while” when Andrew was in junior high school. His mother returned to the area and Andrew lived with her until leaving for Kosovo.

When asked about family support for his college endeavors Andrew mentioned his sisters, aunts and uncles as all being very excited and proud. Andrew's mother is excited that he is enrolled in college, but he has an ambivalent relationship with her.

Mom? Oh yeah, she's pretty happy, but my mom... There's a little bit of a trust issue there. I mean, not, I love my mom and stuff like that but I've never, ever relied on her. But she's incredibly excited that I'm going to school and stuff like that. But I put a little distance there.

Andrew's father was released from prison during his senior year in high school. He moved to mid-Missouri to be near his family. Three years later (in the summer after Andrew’s freshman year in college) his father was diagnosed with cancer and died very 
quickly. His father had designated Andrew as the party responsible for handling end-oflife details. The emotional toll of losing his father, plus a car accident, an effort to run a painting business, and his struggles with math, all proved to be too much. Andrew failed his classes and was dismissed from the university.

The summer of 2010 was kind of rough. My dad we found out had cancer. And he died a week later after we found out he had cancer. I spent a lot of time with my dad. Because, I'm nine of 10, but I was the one left in charge. 'Thanks a lot Dad, I appreciate it!' So I was spending a lot of time with that so I lost a month. I was behind. I ended up flipping my car. I had just moved five miles away from campus and I didn't have transportation to get here. So I was working on my roommate's schedule and sometimes if I wanted to get home I'd have to skip a class and it didn't work out very well so I ended up failing out.

Andrew enrolled at a small college in the area, improved his grades, and has been readmitted to the university. "And I took a little while off. Thought about some things, took a good hard look at what I wanted to do. I took some time away, figured some things out and came back.”

Andrew's father is not the only one who has identified Andrew as the "capable one” in the family. Three of Andrew's brothers have felony convictions and two want to rely on Andrew for material and financial support.

My brothers...three of them are felons. Two of them are in and out of jail. But yeah, so, they're knuckleheads and I mean they have all, in the last year at one point in time slept on my couch for periods of time because they can't seem to find steady work. But, I mean they respect what I'm doing, they're happy that I'm doing it, but they're like, "You can take care of us when you're out of college." And I'm like, "No, that's not how it's gonna work. I'll help you, but I'm not taking care of you.”

Andrew and his family perceive him to be a cornerstone in his family. Being able to support himself and his mother and siblings financially is one of the driving forces 
behind his pursuit of a college degree. When things get tough, it is his sense of responsibility for his family that motivates him to continue.

The reason I go to school is because my family... I mean, I might be nine of ten but a lot of people rely on me in some way, shape or form. But that's something, when I had that break in school it's like, sitting around saying, let's think about this. Why did you do school in the first place? Like who's relying on me, who am I going to let down if you don't do this? And that helped me get back in the gear of things and just get focused and get off my butt.

\section{Lillian: Career military.}

Lillian is a full-time employee of the university. She is in her early fifties and is a single parent with two children, aged 26 and 28. She hails from the western U.S. but has called Missouri home since retiring from the Navy in 1996.

Lillian came from a military family. Her father was in the Air Force, so she lived

all over the world as a child. She says enlisting was an easy decision. "My parents wanted me to go to college and I didn’t want to go to college right away. I wanted to explore and see the world. So I just enlisted.”

Lillian said she has always aspired to earn a college degree. She has made incremental progress towards this goal both during her time in the Navy and since retiring in 1996. As a single parent though, Lillian has always struggled to find a balance between her school work, her military and work obligations, and her obligations as a parent. She tried to earn college credits on and off throughout her service career but found it too difficult with two small children.

But during my military career I tried to take a few courses here and there and that was always really difficult. Trying to be a mom and a military person and going out on maneuvers, and being deployed somewhere for 
two weeks or six weeks, and trying to stay on top of things. It just didn't work. So I said well, as soon as I retire then I'll go to school.

In 1996, Lillian retired from the military and moved to a small town in Missouri. Her multi-racial children began to get picked on in school. Her son received notes with Swastikas on them saying "We hate Jews" and was assaulted on the playground. Her daughter received unwanted attention from the boys. Within two years she relocated to Columbia. She enrolled in the university and lived in student housing. She thinks of this as a very positive time in her life.

I enrolled at MU and my children were in middle school so I thought that that would be a good time to get started. And I was a full-time student here during the day. I loved going to school every day and coming home and doing homework and having all of that going on with my children too.

Once again, obligations to her children took precedence and Lillian had to stop out of school. This delay, though, had financial implications as well. Lillian was operating under the Montgomery GI Bill, and so had only 10 years in which to use her benefits. By the time she was able to start school again that period had elapsed.

But, raising children during their middle school years is very difficult. And we were also going through some traumatic family adjustments, so about two years is all I got. And then I had to stop altogether and then look for a full-time job or a part-time job and then just be focused on being a mom. And so I think, you know, that postponement, you know, was somewhat detrimental to me financially because by the time I came back to school I no longer had any [GI Bill] benefits.

In 2010, Lillian started in the evening program at the university. Classes were held on campus. She enjoys the perspectives and knowledge of her younger classmates and appreciates their facility with technology. 
Oh yeah! Yeah. And actually what was great too, being a non-traditional student, I'm in my fifties, being exposed and being around the younger students also is very helpful because they have such a perspective of what's going on in life and society today that I don't necessarily see from that perspective because of my age, you know, the age gap.

Though Lillian appreciates aspects of her younger classmates, she also feels that they are immature. She feels like she is working much harder than her younger classmates.

As an older student I have to apply myself a whole lot more. And so it's a little frustrating to hear [the younger students] whine. It's like, get real. Get a clue. Grow up. Really, you don't have time to go play with your friends today? You don't have time to hit the bar tonight? School is getting in your way of your life? Oh. Oh. Poor you.

Because it's really hard to be 50 years old and trying to work full time and then still try to fit this in. And my brain has not been exercised to the extent that it's easy for me. You know [the other students] can read a chapter ... and they might wipe it out in an hour, where it takes me three hours. Because I have to re-read and re-read because even words, some of the vocabulary, is so different than what was used in college during the time that I would have gone.

She compared herself to younger students in the classroom whose knowledge is

more current because they have not had a break in their academic activity.

I have a huge gap of time that has passed that I have not worked my brain in the way that they have continuously been able to work their brain, going from high school and right in to college. So the information they're learning in high school has prepped them for what they're learning in college right now, which makes it an easier transition.

Lillian does credit her experience in the military with providing her a greater appreciation of diversity. She believes this gives her an advantage both academically and professionally.

But I do still feel that my experience of being exposed to different people and cultures and their world, their life, their food, the way they live, love 
and learn, brings a lot to the table in being able to manage people. And I think as a manager or a supervisor you have to know that that exists. Otherwise you're not going to be as effective as maybe your company needs you to be.

As a career member of the Navy (and coming from a military family) Lillian grew up in the military culture. She felt a strong sense of community within her military "family" and bemoaned the loss of this readily available emotional and tactical support. “And because you're so far away from your family, you know, especially when you're overseas, your biological family, you establish family networks with your neighbors and your coworkers." "It's kind of like this family unit where everybody kind of fills in where someone else can't and you kind of take care of each other. And I don't see that out here as much. And when you're going to school and you're working it's difficult.”

This support was especially important to Lillian as a single parent. She spoke of the support systems found on base, such as affordable, trustworthy, easily accessible childcare and recreation facilities. Lillian said the lack of such trustworthy and affordable resources made it difficult to be a single parent and go to school in the civilian world. This was one of the factors that led her to stop out while her children were in middle school.

Because she works full-time and takes online classes, Lillian finds it difficult to make any connection with campus veterans. She would like to participate in activities with the Mizzou Student Veterans Association (MSVA) but she works in an off-campus location. Coming to campus during her lunch break is not an option due to lack of available parking near the Veterans Center, and lack of time at lunch. MSVA activities 
are also typically offered either during her work hours or at times that she must be logged on for one of her online courses. She is very frustrated by this as she longs to associate with other veterans. "And I don't feel like I have a connection to any military or veterans' services or other veterans. I kind of feel like I'm out there on my own.”

Lillian feels isolated from the military community, which was a significant part of her life. She longs for friends she knew while in service. Her best friend and longest-term source of support lives in Guam, and Lillian plans to go visit her once she graduates.

A significant emotional blow for Lillian was the loss of status and income once she retired from the military. Lillian worked as a training and development coordinator in the Navy. She trained hundreds of people, developed curriculum and provided career counseling. However because she does not have a college degree, she is unable to obtain a job of similar complexity and status in the civilian world.

I am making less money now than when I was in the military. Considerably less, even though the military is one of the lowest paying jobs in the country for what we do. And it's been rather difficult to raise kids, you know, on a very minimal.... Actually when I started with the university seven years ago I started at $\$ 7$ an hour. And it's because I don't have the degree to get into those positions that have a better opportunities for advancement.

And so now I'm struggling to have to go to school to try to get just that piece of paper - I think it's pretty frustrating. It's very demeaning. So I pretty much...keep plugging away at my books and my homework, and just hoping that at the end of this tunnel of being able to get this degree I pray that then my age won't be a factor in me being able to get a job that pays more than the $\$ 12$ an hour I'm getting now.

Lillian's goal is to earn her degree and move into a better-paying position so that her retirement from the university will be based on a higher salary than she currently earns. "And then as a single woman I just have to be able to prepare for 
being able to be sustainable, self-sustainable. Yeah, and what kinds of things do I want to do when I retire? And then do I have those resources available? Have I set myself up appropriately?”

Lillian is finishing her degree through the evening program at the university. Initially this program offered classes on campus, but recently it has switched to an onlineonly format. This is very disappointing to Lillian. She mourns the loss of the relationships she had with classmates.

Believe me there was a time when I thought I should just quit my job and go to school full-time, and just go during the day so that I could get that interaction, so that I can get that feel of being part of the campus, so that I can walk from one building to the other, and feel like I really belong here.

Lillian is also encountering challenges with her health. Shortly after restarting school in 2010 she was diagnosed with a medical condition that requires daily medication. This medication makes her drowsy and compounds the difficulties she already experiences as an older student who is working full time.

Lillian has 24 credit hours left to complete her bachelor's degree. The tuition benefit from her job and the proximity of her completion conspire to keep her going. "I really hate the online environment. But I'm so far into it now that I can't go somewhere else without suffering. I'm cornered. I'm trapped.”

\section{Scott: College is harder than he thought.}

Scott is 26 years old and grew up in a small town in mid-Missouri. As he neared the end of high school Scott realized he did not have the skills or education to pursue a meaningful career, and feared he would be faced with a dead-end job. He decided to join the Navy as a way to postpone that outcome. 
Even though I told everybody when I joined the Navy that it was to pay for college it was, okay, my choices are get a job that I don't want. You know, I don't want a job, I want a career. I'm too scared to go to college and I don't want to go to a job, so I'll just join the Navy and get out of town. And I have to sign up for four years so I guess I'm free of making decisions for four years.

Through friends and coworkers that he met while in the Navy, Scott

developed an interest in building motorcycles. His hobby developed into a

passion, and he realized he had finally found an area of inquiry that might sustain his interest as a career.

I just started wanting to be a part of that and do it myself. And the longer I got into that as a hobby, the more attractive stuff like that started to be. Once you've exposed yourself to that stuff for so long you kind of start to get the wheels turning and, oh, okay, I kind of can see how that would work better even though it looks strange. If this works better I really want to, you know, build stuff that looks weird and works well.

After a little over six years in the Navy Scott decided it was time to do what he had told everyone he would do - go to college. Though he had taken some coursework while he was enlisted, none of that bore a grade. Without a grade point average Scott could not transfer into the university, so he spent a semester in a local community college. When he transferred to the university he was surprised at the work load.

I wasn't prepared...for how demanding college is. I don't know if anybody could be. I did one semester at a community college before. But, I don't know, a university and a community college are two totally different ballgames. I did not see that coming. I mean, the same amount of hours at a community college was a joke. I thought man, if college is like this I'm headed for a degree quick. I'm not even gonna work at it.... I'm workin' at it here.

Scott described himself as a "typical slacker” who didn’t plan on college and thus took only the required minimum classes to graduate. Looking back he regrets not doing a better job of preparing for college. 
So not only did I not work hard enough in high school to prepare myself for this, I also have gotten rusty on a lot of those skills over the past however many years you know. [Soon it] will be nine years since I graduated high school. So I feel like I'm playing a little bit of catch up there. I mean, it's my own fault. I mean, I didn’t fail stuff, but I could have set myself up so much better, working harder in high school.

Scott is especially struggling with math. He took only the most elementary math classes in high school. As a result he now finds himself taking a lot of introductory math classes (e.g. college algebra) which are pre-requisites for the more advanced classes required for his degree in mechanical engineering. Scott also took some dual-degree classes in high school that will count as credits in non-math areas (e.g. English and arts classes). Surprisingly this is causing problems for him now.

A lot of the dual-credit I did in high school was gen-eds. So I mean, I'm never going to have to take an English course...because I did everything required for a mechanical engineering degree, I got the credits in high school. Well, that's an easier course...that is not gonna be part of my schedule. It's gonna be replaced by something more difficult.

This will have an impact on the mix of classes Scott will be able to take each semester. He will soon be in a position where every class is one that counts towards his major and none can be allowed to "slide."

Yeah, what worries me is I think I'm getting into a position where I've got so many gen-eds and specifics knocked out, unless I take a really light class load, I'm going to be in a position before long where every, you know, I'm taking a full load of serious classes. There's not a class that can, you know... That prioritizing? When it comes to making decisions about what falls by the wayside? Nothing gets to fall by the way side.

This will also have an impact on how Scott uses his GI Bill benefits. Students must be enrolled in a minimum of 12 credit hours in order to collect full benefits under this program, though most undergraduate enroll in 15 to 16 hours. Scott is afraid he will 
soon be faced with a choice of taking fewer classes per semester and thus not making maximal usage of his benefits, or taking a class that will not count towards his degree but will lighten his load. Because it will not count towards his degree, the GI Bill will not pay for such a class; Scott will have to pay for it out of pocket.

While Scott admits he did not prepare well in high school, and his academic skills have gotten rusty since that time, he does credit his time in the military with helping him to mature.

Yeah. I am glad I did the military thing before I went to college. I had no desire to go to college immediately after high school anyway, but if I had of and had started it immediately I would of, I can't imagine that going very well. If not for the Navy, you know, teaching me how to be somewhat of an adult, I can’t imagine the college thing going very well.

Scott spent six years in the Navy and during the last year and a half he moved into positions of leadership. He credits this experience with teaching him strategies that are aiding him in college.

I only had about a year and a half of that leadership experience before I got out of the Navy. But I've seen some of that that I have to do now, that that limited leadership experience kind of prepared me for.

I wish I had a longer time experiencing that leadership in the military before I got to this point. Um, I think just that extra ability to prioritize and, I mean. I don't feel like I make the right decision on some of that stuff all the time. I'm getting better at it. This is only my second semester at MU. I'm slowly getting better at, I don't know, time management and prioritizing what needs done. And if everything doesn't fit in what can kind of fall by the wayside and not be a disaster. But I'm not there yet, there's room for improvement.

Scott also commented on other aspects of the transition from life in the military to life as a college student and civilian. One area was the difficulty of moving from the 
highly structured environment of the military to the much less structured environment of the college campus.

...you're going from a lifestyle where it's so structured and you're told what to do practically every hour of every day to on this campus you're more than welcome to walk out of a classroom and ignore everything, you know, not read anything from a textbook, not do any homework. Nobody's gonna babysit you.

Scott said civilians seem to believe that military veterans are "hard chargers" who will do all they need to do without any effort. He acknowledged that he developed selfdiscipline and the ability to prioritize while in the Navy, but seemed to feel that civilians did not understand how difficult the transition could be.

Well, there's a lot of structure there and there's not much here. So you have to have the willpower to do what needs done and to be smart enough to decide what needs done. You don't have a drill sergeant yelling at you telling you to do your homework. Professors aren't gonna do that. You're not getting babysat anymore.

Another aspect of the transition that is hard for Scott is leaving behind the "Navy thought process." He spent six years in an environment where communications were blunt and to the point and "if you screw it up, you're gonna hear about it." He is struggling to make the transition to a different manner of communication.

You know that really blunt, directly to the point, you know, personal responsibility way of doing business kind of needs to be toned down when you're not in the military any more, and it takes a while to do it. Civilian life doesn't happen like that.

I've kind of learned there's a brain-mouth filter that has to be there. It's not offensive and it's not mean, it's just necessary. Except it's not necessary any more. 
This is especially apparent to Scott when he thinks about his experiences in the classroom. Scott contrasted his own personal growth and maturity vs. his classmates by referencing a popular movie, Billy Madison.

Soon after I started coming to school here I saw a thing on the internet. It's a picture from.... I believe it's the movie Billy Madison. Adam Sandler goes back to elementary school as an adult and he's surrounded by eightyear-old kids, but he's 25 . I feel like that every day in class. I feel like I'm surrounded by children. And I don't mean that in a derogatory way, it's just like, you know... it's a massive difference in I think life experience.

Scott is used to receiving and executing orders in a rapid and efficient fashion, knowing that the current mission and the well-being of his comrades depend on his hard work. When his civilian classmates don’t assume the same level of personal responsibility he finds himself having angry internal dialogues about their immaturity.

Well, somebody does something stupid in a classroom and for months I had these images of man, this person needs to be put in their place. I mean, the professor gives very detailed directions on how to do something and some idiot raises their hand and asks what they need to do. Well he just told you what to do. Shut up and do it.

Looking back on how he has changed Scott is surprised, and perhaps a little

worried, about the difference between what he was like in high school vs. what he is like now. He says his military mind-set is slowly moving into the background as he becomes more accustomed to civilian life, but he is still struggling to find an appropriate balance.

It still blows my mind that that's how my thought process works because I'm not naturally an assertive person. I'm the shy quiet guy in the back corner of the classroom that, you know... I was decent in schoolwork but I was not confident or anything resembling confident. And the Navy totally changed that and now I'm almost... By civilian standards I've gone, you know, past the appropriate line of confidence. I'm two totally different people between high school and getting picked on and now in college and thinking, "I'm surrounded... I'm Billy Madison and surrounded by eightyear-olds. 
For Scott, part of making the transition to civilian status has been a decision not to

reveal his status as military veteran. He is concerned that if he reveals this piece of his history that people will ascribe qualities to him that match their stereotype of a "sailor."

He doesn’t want this to get in the way of "honest" interactions with classmates.

I find it a lot more interesting to see how people interact with me, not having a clue. I feel like I'm a college student just like everybody else. ...I've been in some classes where some pretty interesting conversations came up regarding the military that I don't think would have happened if I was more vocal about that. And I want to be a part of that and hear.... It's almost like sneaking in and okay, what do people really think? I'm interested in people's honest opinions.

Scott credits services provided by the university as assisting him with some of the nuts and bolts of being a military veteran college student. Foremost in this area is assistance with GI Bill benefits that is provided through the campus Veterans Center.

They're very helpful. I don't know how much effort goes into it but I know it's not a lot on my part, so it must be quite a bit on their part. Yeah, and you know, when you walk in there and...they have a pre-sorted stack of paperwork and it's like, "sign your name here...." And you give it back to them and they take it from there and a few weeks later you get an email from the VA and everything's paid for.

Scott also appreciated Summer Welcome, the two-day campus orientation program for incoming freshmen held in June and July.

I mean, when I came in as a freshman, the Summer Welcome, I mean that process was painless. I'm used to being pointed in the right direction and then having to go do the rest myself. And Summer Welcome it's like oh wow, I've literally got somebody just walking me around campus. You know, not much effort at all involved.

Through Summer Welcome and the Veterans Center Scott learned of free tutoring offered to veteran students. While has not used it yet, he appreciates the existence of this 
service and anticipates making use of this resource as he begins to take more difficult math classes. Similarly, Scott also had heard about a veterans-only section of Learning Strategies, the university's version of a first-year experience course. Scott did not enroll in this class but had a positive impression and perceived it as a useful service.

I don't think it was worth very many hours, but whatever credit it is, it falls into the category of things I really don't need more of. But it's some kind of a transition assistance, like... And it's for veterans only. I would think that would be the productive part of that class, to help veterans transition from okay, "here's what your life has been like”... Kind of like a boot camp for college.

One campus service that is targeted towards veterans is the Mizzou Student Veterans Association (MSVA). Scott does not participate in this group. He says this stems from his desire to transition back to a civilian way of life. But his statement seems to also reveal feelings of ambivalence about his time in the military. He is proud of his service and recognizes the benefits he gained, but he wants to put it behind him as quickly as possible. He has "no desire to specifically target other veterans for relationships, friendships, whatever.”

Uh, I am glad I spent my time in the Navy and if I had it to do over again I would the same thing over again, but I thank God I'm done with it. And I do not care to go back. I have a handful of really close friends that I'll probably talk to until the day I die from my time in the military.... But if I go to the Veterans Center and start hanging out with some guy who was in the Army for five or six years, we're constantly gonna talk about the military. I'm more interested in moving back into civilian life, not getting myself stuck. You know, it's difficult enough without being around people in the military all the time, to get out of that way of doing things. Because I mean yeah, it's very effective and I'm sure it changed me forever, but at the same time I want to get back into doing civilian things and doing it effectively. 
An important source of support for Scott is his family. Scott lives with his sister and her family in a nearby small town. When he was in the military, Scott felt lonely and homesick. He is glad to be home. Living with his sister also helps him to stretch the support he receives from the GI Bill. "I live with my sister.... It's not comfortable for anybody but it doesn't make financial sense to pay rent in a place where the only thing I need to do there is sleep. I'll grin and bear it for a few years and then I'll get out of college and move on.”

While living with his sister's family helps financially and provides a feeling of support, Scott wishes he could live in Columbia. His long commute to and from campus leaves little time for socializing or participating in study groups after school. He also believes that by living in Columbia among fellow students he would be able to develop networks of friends that would ultimately benefit him academically and professionally.

I mean, for the most part I come to campus and go to class and go home. And I really wish my financial situation was different and it made sense for me to live in Columbia instead, because I feel like, what MU has to offer, I could reap more benefits from that living closer. Uh, you know, there are evening study sessions or library resources or whatever it is on this campus. Having 24/7 access to that would help a lot. And I kind of get the feeling that a lot of college is networking and relationships and stuff like that. It's not just okay, I'm here for a class and a piece of paper. You know, I think there's a lot more that can be gained from it rather than just the degree.

Scott will be the first member of his family to earn a college degree. While his family voices overall support for his efforts, they provide a mixed message of support for college-related behaviors. For example, Scott's brother-in-law will make sarcastic comments that belittle Scott's passion for his field. 
Well I get on some kind of topic that I'm really passionate about you know, and talking about it at home, you know, and my brother-in-law especially will make some comment. "Oh you're just using big words. You don’t actually know what you're talking about. You're just trying to sound intelligent."

Despite his lack of academic preparation, rusty skills, long commute, and the struggle to transition to a civilian way of life, Scott is persevering in his academic efforts.

The factors that motivate Scott to stay in school and persist to degree completion could be described as both a carrot and a stick. The promise of a fulfilling career is one thing that motivates him to continue.

Honestly, probably even more than the degree and the career that I'm hoping for afterwards is the challenge. I think there's a wide variety of directions this degree could take me when it comes to choosing a career afterwards but I think a lot of those options will be challenging and I can continue to, you know, dangle that carrot in front of myself and, you know, keep learning and pushing the boundaries of, okay, how much can I, you know, wrap my head around and how much of this can I pull off?”

Scott's tremendous determination and the self-discipline he learned in the military also keep him going. These represent the “stick” he uses to urge himself along. He simply makes himself follow through on a task even if it is hard.

I have to sit down ahead of time and make that decision and then never look back. When it came to joining the Navy and when it came to reenlisting and when it came to going to college, it's always a process, for me anyway, of okay...I'm gonna finish this. There's no backing out. And when it comes time for well, I've got an essay due and I need to study more for an exam tomorrow, and there's all these things are piling up in college it's like well, that's tough. I made the decision I'm gonna finish this, so I'm gonna finish it.

Scott's program is academically rigorous and at times he feels like giving up.

During those times he reflects back on his time in the military.

I mean, I'm a little discouraged at times seeing how much work it takes and thinking about how much longer I have to go. But uh, any time I'm 
thinking about oh, I gotta slack off and I just need a break, well there's not time for a break. I spent six years being miserable to get to where I am today so that I could go to college because I couldn't afford it without the Navy. Why would I have spent six years being miserable just to get to this point and give up? That's not gonna happen. If I can survive six years in the Navy I can survive four years at MU.

\section{Cross-case Analysis}

This study sought to explore the institutional and personal factors that both support and impede the persistence of undergraduate military veteran students. Because very little research has been done on the veterans returning from the conflicts in Iraq and Afghanistan, this study employed an exploratory case study format. Semi-structured interviews with current veteran students were conducted over a six-month period. Analysis of the data from this study revealed that these veteran students have characteristics in common with both traditional and nontraditional undergraduate students. Additionally, three of these students will be the first in their families to earn a four-year college degree.

Five overall themes that play a role in the persistence of these veteran students were identified. These include academic challenges, a struggle to balance school work with outside obligations, the transition to civilian life, support from significant others and from the institution, and goal orientation.

\section{Academic challenges.}

There was a strong feeling among these students that attending college is much more difficult than they had anticipated. These veterans acknowledged the difficulty of being a returning student in the classroom alongside students who have not had a break in their academic activity. They bemoaned how "rusty” their academic skills had become. 
They talked about their surprise at the difficulty of college, and the challenge of transitioning to an environment that is less structured than the military. Technology has advanced since they were in high school, which also presents challenges. All four felt some blow to their confidence when comparing themselves to students who did not have a break in their education.

Like nontraditional college students, all four veterans have returned to college after a period out of high school. Scott, Amy and Andrew acknowledged their academic skills have been dormant (especially their math skills) and some felt that they had not prepared adequately while in high school. Scott described this as having to play "catch up.” He also called himself a “typical slacker” who didn’t plan on college and thus took the bare minimum of classes to graduate.

For Amy, the amount of reading, number of class projects, new technology, and classes in statistics and Spanish combined to create a "tough" experience, which has been a blow to her confidence. She struggles with feeling "old" and "dumb," even though she was one of the top students in her high school.

Andrew also felt the effect of letting his academic skills become dormant, especially his math skills. He described adjusting to this gap between high school and college as having to relearn "how to learn.” Andrew felt like this adjustment took a full school year and that he was back on track by his second year.

Lillian is an older student with a full-time job and health issues. She identifies these qualities as making it hard for her to read and process as quickly as younger 
students. She has adjusted her work schedule to allow her more time in the evening for school work and for her online classes.

Amy and Lillian also spoke of the advances in technology since they were in school and how they have to rely on their younger peers to assist them with devices and software. Amy graduated high school in 1999 and computer technology has changed substantially since that time. She was dismayed to learn that one of her classes would require her to create a video in iMovie.

Scott, Amy and Andrew are all first-generation college and thus do not have a college-going tradition in their families of origin. This means they did not grow up with a family member who could coach them to prepare for college through high school classes, or who could guide them in developing study skills and other self-discipline measures required for college success. They had no one to warn them about how hard it might be to return to school after time away.

Scott said he wasn't prepared for how demanding college is. Though he took a few college prep classes in high school he did not take the experience seriously. He did not see himself as college-bound at that time. When he was discharged from the Navy he spent a semester at a community college, an experience that led him to believe college wouldn’t be much work. As he said, “I’m workin’ at it here.”

Amy also felt like her high school did not prepare her well for college. She wishes her guidance counselor had told her about the language requirement in college so that she could have taken more semesters of Spanish while in high school. She also wishes 
statistics had been offered at her school. And she acknowledges that her mother is not a good resource (she thought Amy's ACT report meant she had been accepted at a college).

Part of the challenge for these students is the lack of structure on campus compared to that of the military. Scott commented that people seem to think military veterans are "hard chargers" who will do all they need to do without any effort. But the transition to an environment with less structure meant Scott had to develop an ability to prioritize academic tasks and the willpower to tackle assignments, without having a drill sergeant available to push him. Andrew also acknowledged the need for personal discipline, especially when it came to doing homework. Andrew talked about the fast pace of the college classroom and the fluid nature of class scheduling.

The good news is all four veteran students felt a boost from their wider perspective and greater knowledge of the world. Like other nontraditional students they have been able to interpret the new knowledge they are gaining in college in the context of their earlier experiences. They perceive themselves to be more mature and knowledgeable about the world, which is a boost to their confidence.

\section{Struggle to balance.}

Along with adjusting to life on a college campus, these students are also struggling to balance the demands of school with their personal life and outside obligations, something they have in common with nontraditional students. For two of these veterans, parenthood presented a significant challenge. As a single parent, Lillian has always struggled to find balance between her school work, her military work obligations, and her obligations as a parent. She has started and stopped school for over 
20 years and still has not earned her bachelor's degree. Her employment and her children always took priority. Now that her children are grown and she is working full-time on campus, she is finally able to finish school.

Amy is also a single parent. She and her daughter moved in with Amy's mother for her first semester in college, but Amy found the combination of parenting, commuting two hours daily and school work to be too much to juggle. She finally asked her exhusband to take temporary custody of their daughter. With her daughter gone, Amy moved to Columbia. Her commute has lessened considerably and she no longer has daily childcare duties. However she struggles with feelings of guilt about being an absent parent. She is determined to achieve her goal of earning a college degree because she believes that will lead to a more secure future for her and her daughter.

Andrew had a different set of family obligations impede his progress. His father died in the summer after Andrew's freshman year and he was left to handle end-of-life details. He also had a significant car accident and had to rely on a friend for transportation, skipping classes when he had to catch a ride home. He was also trying to run a painting business for extra income, but without a car, and with time off to deal with his father's death, he made very little money. The combination of family and personal issues took a toll and Andrew failed his classes. He took some time off, reevaluated his goals and his major, took classes at a local college to improve his GPA, and was readmitted to MU.

All four participants in this study credited their growth and maturation in the military as being beneficial to them in college (e.g. experience with hard work, personal 
discipline, an ability to multitask, and a broadened and mature perspective on the world). Scott credits his leadership experience in the Navy with teaching him how to prioritize his obligations. This has helped him with time management in college. He describes this as learning what he can do and "what can kind of fall by the wayside and not be a disaster.” Many traditional college students learn this as they progress in school, and many nontraditional students bring these skills from their work experience. Scott is glad he got a head start in the Navy.

Amy also credits her 12 years of military experience for helping her to mature and become more confident. In the Air Force she learned how to respond effectively when a plan or a project didn't work out (rather than falling apart and giving up). Amy also developed work habits that have been very beneficial. She worked long hours, in countries around the world, sometimes in adverse conditions. She learned how to prioritize tasks and how to face challenges. Like other nontraditional students, Scott and Amy have used their experience and perspective to be successful in college.

Scott and others also developed skills for dealing with a variety of people and gained a greater appreciation for diversity through their military experience. From these students' perspectives race, ethnicity and gender are not used to gauge ability in the military. As Scott put it, “It's a uniform. You pay attention to what's on a person's collar and other than that, if they do their job well, you're going to succeed. I think it was a good experience that would prepare someone for a diverse campus.”

Military service provided Amy with a "perspective of the world" that was different from her small town. She was initially stationed in Oklahoma and Texas, but 
then began her service as a flight attendant which allowed her to travel the globe. Amy contrasts her broadened perspective to that of the students who entered the university right out of high school. She believes the work ethic and discipline that she developed from long hours and adverse circumstances give her an "edge” over the other students in terms of maturity, organization and perseverance.

Financial struggles can also pose a significant challenge for both first-generation and nontraditional students. Three of the four students in this study are supported by the GI Bill. The fourth (Lillian) is a full-time employee of the university and thus receives a 75\% tuition discount. All four students say they could not attend college without financial support.

Military veteran students using the GI Bill comprise a unique group in that they have a guarantee of financial support for their college expenses that is neither a grant nor a loan. It is essentially an employment benefit that can be used during service or after one’s service has ended. Only students who receive substantial scholarship support compare.

Despite the support provided by the GI Bill, these students still encounter financial challenges, and these can have an impact on their campus involvement. Scott lives with his sister in a nearby small town as a way to make ends meet, but this limits his access to campus activities. He believes he is missing out on developing an important network of colleagues. Amy noted that the GI Bill does not provide support during breaks from school, which can create a financial strain. She is taking on a part-time job to help stretch her finances, which limits the time she has for homework. Andrew receives Pell 
grants and other scholarships, without which he would have a harder time handling financial crises such as car repairs or delays in receiving benefits (such as the semester when he failed to submit paperwork in time).

\section{Transition to civilian life.}

Another theme that emerged in this study is the challenge of making the transition from daily life in the military to life on a college campus. While all students experience some transition when they enter college, aspects of this transition are unique for students who have been in the military.

Like other cultures or communities, the military has its own language, routines and demands. It is a highly structured, unique environment. This culture encompassed every aspect of these students' daily lives including their work, their place of residence, their daily routines, and many of their friends and mentors. By leaving the military and coming to college they are now immersed in a different culture with students who have significantly less life experience. They have left behind an important community and resources. Some have also left behind roles of significant responsibility and status. As part of this transition though, two students have found meaningful outside activities that support their academic and professional efforts.

One issue all four students spoke of was a feeling that they were more mature than their fellow students and more serious about their education. Amy and Lillian were frustrated by students complaining about how hard it is to make it to class. Scott and Amy were disappointed by students reading Facebook while in class or packing up belongings before a professor is done speaking. Scott, Amy and Lillian all mentioned 
their frustration with fellow students asking questions that are answered in the syllabus. Both Scott and Andrew referenced a popular movie (Billy Madison) to illustrate their feeling of being surrounded by little kids. While all of these students were annoyed by these behaviors they also seemed to take it in stride and perceive it as a given, considering the situation they are in (a residential campus).

Another difficulty faced in this transition is leaving behind a ready-made community with important social supports and resources. This was especially hard on Lillian and Amy. Lillian made a career the Navy and greatly enjoyed the experience. In particular she mentions the availability of affordable, trustworthy and easily accessible resources on base, such as daycare and recreational opportunities, as well as easy access to community members with whom she both worked and lived (parents of her children's friends, coworkers, neighbors). Lillian bemoaned the loss of these resources, as well as the loss of the sense of community she found on base. This was especially important to her as a single parent. Without easy access to these resources Lillian found it too difficult to be a full-time student and a single parent to middle school-aged children, and so stopped out of school.

Amy mentioned the difficulty of being far away from the good friends and mentors she found in the Air Force. She hears other students talk about having a network of friends who give them advice about classes and professors. She wishes she had access to a similar resource where she could get this important information. However, the students in her classes are significantly younger than her so they differ in their perspectives, interests and activities. She doesn't have enough in common with them to 
want them as friends. Amy is caught in the middle. She doesn't want to socialize with her classmates but she doesn't have a nearby network of friends her age. She longs for such a support system, and she also wishes she had a network of classmates who could help her navigate her academic program. She feels alone and lonely.

For Lillian, the loss of status and income upon retirement from the military was a great blow. Lillian worked as a training and development coordinator in the Navy. She trained hundreds of people, developed curriculum and provided career counseling. However, because she does not have a college degree she is unable to obtain a job of similar complexity and status in the civilian world. She is angry about this and feels demeaned. Unlike younger students who see their undergraduate degree as the doorway to a career, Lillian's degree (a Bachelor of Arts in General Studies) will simply serve to help her get a better-paying job. It does not hold the promise of an exciting new career and development of a new identity.

Amy was also in a well-paying position of some prestige in the Air Force and sometimes asks herself why she left it all behind. Unlike Lillian, Amy has found an undergraduate major that excites her and is preparing her for a career she believes she will enjoy. She is also young enough for this career to bear fruit in terms of income and retirement. Lillian made a career of her Navy service and found it to be a satisfying choice. Amy’s work in the Air Force did not match any civilian careers that she wished to pursue (she didn't want to be a flight attendant). As such, making a career switch was easier for Amy, and not as much of a blow to her identity. In this way Amy is more like 
traditional students or those nontraditional students who have secure, satisfying employment and are attending college as a way to progress in their career.

Scott is pleased to be making the transition to civilian life but is finding it to be challenging in ways he never expected. After six years in the Navy he is having a difficult time leaving behind the "Navy thought process." Scott describes himself as being shy and introverted during high school, the kid who got "picked on.” He credits the Navy for helping him to mature. He is more assertive now, which he perceives to be positive. However he worries that he might be overdoing it. He finds himself having angry internal dialogues about the immaturity of his classmates. Scott said that he was very grateful for his time in the Navy and does not regret his choice. But as he says, he is ready to put that behind him and get back into thinking and doing things in civilian ways. Part of that transition is the struggle to maintain his new assertiveness while letting go of the "in your face" communication style he learned in the Navy.

For Scott, part of making the transition to civilian status has been a decision not to reveal his status as military veteran. He is concerned that if he reveals this piece of his history people will not see him for the civilian he is trying to become, and instead will ascribe qualities to him that match their stereotype of a "sailor." He does not want others' pre-conceived notions to get in the way of building relationships.

Andrew is more willing to reveal his status as a veteran but is still cautious about when to do so. When the subject of the military comes up in class he occasionally contributes to the discussion, and he has had professors and classmates thank him for his service. But sometimes friends reveal his status for him. This can be an uncomfortable 
experience, especially when people ask if he killed anyone (something that regularly happens at parties).

As part of their transition out of military service two of the participants in this study have found meaningful off-campus activities that support their academic and professional interests, and provide social support. This involvement has eased the transition for both of these students. Interestingly, both activities are related to the military.

Amy has joined the Air National Guard as a way to gain practical work experience. She identified the Public Affairs division of the Guard as a good option. She began attempting to get a position in Public Affairs even before leaving the Air Force but met with resistance from the recruiters who wanted to place her in other areas. Amy persevered and after a year was able to get hired on in that division. This choice will provide financial benefits including a paycheck and health care. Amy will have to take a semester off from school however, in order to receive training. For Amy, this break in school is a small price to pay for the financial and professional benefits she will receive. She also anticipates she will be able to make new friends who are closer to her in age and experience.

After realizing that a degree in engineering was not for him, Andrew switched his major to psychology. He is volunteering at Welcome Home, Inc. through the university's Service Learning Program. For Andrew, this work is important on both a personal and professional level. He is excited to be learning more about social service. He also is 
excited to serve other veterans, especially those who are homeless. That issue is one that Andrew himself came close to facing in his life.

These extracurricular activities provide a tangible connection for Amy and Andrew between their course work and their professional goals.

\section{Support.}

\section{Support from significant others.}

The students in this study draw support from a variety of sources, but three of the students in this study shared a sense of isolation. Andrew is the exception. He lives with fellow students he met during his freshman year. He also has a tight group of friends he has met through classes and other activities. He likens this group to his squad in the Guard. Because he lives and socializes with fellow students, Andrew is more like a traditional student.

Amy wishes she had a group like Andrew's. She moved in with a roommate in January but that woman works evenings and is busy with her boyfriend on the weekends. People on campus have suggested that Amy might find friends among the graduate student population but she doesn't attend classes with those students and so has no natural opportunity to get to know them. Though she is near her home town and old friends, Amy longs for her friends from the Air Force who she perceives as being the people who know her the best.

Because she works full-time and takes online classes, Lillian is unable to make any connection with campus veterans. She feels isolated from a community (military members) that was a significant part of her life. She, too, longs for friends she knew 
while in service. Her best friend and longest-term source of support lives in Guam, and Lillian plans to go visit her once she graduates.

None of the students reported negative experiences with faculty members, but only Andrew reported seeking assistance from professors. He has consulted his instructors about class work, especially when he was still an engineering major and struggling with math. He characterized those interactions as being easy to establish and very helpful. Amy also reported reaching out to a professor to give positive feedback about a particular class assignment. But that lone interaction seems to have been the limit of her engagement with faculty.

All of the students reported receiving positive feedback from their families regarding their choice to attend college. Three of the students are first-generation college and their families don’t fully understand their experience. Amy describes her mother as uneducated. Her mother has no understanding about Amy's experience and she finds herself having to provide her own reinforcement. Amy recognizes that her mother is proud of her but she wishes she had a better grasp and was more involved.

Scott receives material support from his sister (he lives with her family and helps with expenses) but it comes with a cost - a sarcastic brother-in-law who belittles Scott's passion for his field. Andrew's family is proud of him however his three brothers see his success as their meal ticket.

\section{Support from the institution.}

The University of Missouri already has a robust set of programs and services aimed at fostering academic and social integration including a summer orientation program (Summer Welcome), Freshmen Interest Groups (FIGs), a first-year experience 
course (Learning Strategies), numerous student groups, undergraduate research opportunities, and a variety of academic support services (individual and group tutoring, advising). Since 2009 MU has provided veteran-focused versions of some services including outreach to veterans during Summer Welcome, a Veterans Resource Center, a veteran student group, free individual tutoring, and a section of Learning Strategies. Three of the students in this study (Amy, Scott and Andrew) took advantage of these veteran-specific services to varying degrees.

Scott and Amy both participated in the Summer Welcome program, a two-day orientation to campus. They found it to be very helpful as a general orientation to campus for new students. The information they were given about campus services specific to their status as veteran students was helpful. They were especially glad to learn about GI Bill processing by the Veterans Center and the free individual tutoring offered to veterans.

Both traditional and nontraditional students are concerned about finances and navigating the billing and financial aid systems at college can be a struggle for any student. Veteran students are in a unique position in that they have significant financial assistance through the GI Bill. The GI Bill covers the cost of tuition, books and housing, but the bureaucracy involved in obtaining benefits can make it feel like one hurdle (financial worry) has been replaced by another. The Veterans Center on campus helps process the GI Bill benefits. Amy, Scott and Andrew are supported by the Post-9/11 GI Bill; Lillian's eligibility for the GI Bill expired several years ago. The students who are using the GI Bill cited the organized, efficient services offered through the Veterans Center as being helpful and easy to use. 
The Mizzou Student Veterans Association (MSVA) is the veterans-only student group at the university. This group received mixed reviews from the veterans with whom I spoke. Andrew, who is still enlisted in the Guard, finds it to be a positive opportunity. He has attended some of the meetings and has participated in the group's activities including an annual summer float trip, and an annual lunchtime cookout called Operation Free Lunch.

Amy tried participating in a couple of MSVA activities but felt a little out of place. She discovered that the group was made up largely of men who had been in the Army. As a female veteran of the Air Force she felt like she did not match up with the group. Scott states he wants to make a full transition back to civilian life and has no desire to hang out with other veterans.

Students on campus have access to group tutoring sessions on specific topics but certain groups of students (e.g., TRIO/SSS students, student veterans) receive individual tutoring at no cost through the campus’s Student Success Center. The three on-campus students were aware of this option and were very impressed that the service was free. Amy has utilized this service and believes it is making a big difference for her in both Statistics and Spanish. Scott anticipates using this resource as his classes increase in difficulty. Andrew especially appreciated assistance with his advanced math classes.

Beginning in 2009 the campus offered a veterans-only section of the first-year experience course titled Learning Strategies. This course provides guidance for all aspects of college life, with a focus on academic skills. Andrew enrolled in this course in his first semester and found it to be very useful. He learned a great deal about studying, 
time management, and self-discipline (some of which he didn’t appreciate until a couple of years later). After two years the veterans-only section of this course was cancelled due to low enrollment.

Andrew, Amy and Scott have been able to take advantage of these services because they are attending school full time during the day. Lillian feels left out of this picture. As a full-time employee who works during the day she has limitations and challenges that are characteristic of other nontraditional students. Lillian would especially like to participate in activities with MSVA or the Veterans Center however she works full-time for the university in an off-campus location. Coming to campus during her lunch hour and finding parking near the Veterans Center is nearly impossible, so visiting there does not feel like an option. And activities through MSVA or the Veterans Center are offered either during her work hours or at times that she must be logged on in the evening for one of her online courses. She is very frustrated by this as she longs to associate with other veterans. Lillian was also unaware of the Facebook pages for MSVA or the Veterans Center and so misses out on that option to connect socially with other veteran students.

\section{Goal orientation.}

Each of the students in this study has differed somewhat from the others in their path through the military and in college, and each is facing challenges while in school. The factors that motivate them to persist (the promise of a worthwhile career, greater job opportunities, a sense of responsibility to family) as well as the perseverance and determination that each learned while in the military help to keep them in school in the face of difficulties. 
Lillian, Amy, and Andrew are all motivated in part by their commitment to the broader goal of earning a college degree. They believe such a degree will open doors and thus provide greater financial security due to better employment opportunities. During her time in the Navy, and since retiring in 1996, Lillian has made incremental attempts to complete her college education. She wants the degree because she loves to learn and because a college degree is something she has always aspired to. She also knows a college degree will be useful in terms of employment and promotion, and thus for financial security.

Andrew enlisted in the National Guard during his junior year of high school because he needed a way to pay for college. Andrew wants to help support his mother and siblings financially. He believes that having a college degree will provide greater employment opportunities and thus financial security. When things get tough, it is his sense of responsibility for his family that stimulates him to continue. This commitment motivated Andrew to rectify the situation when he was dismissed from the university due to poor academic performance. He took time off, evaluated his situation, took classes at another local college, and was readmitted to MU. At that point he changed his major to one that is more in line with his interests and abilities.

Like Andrew, Amy was a good student who came from a poor family. The military had never been part of the plan for her, but when faced with how to pay for school her plans changed. Amy enrolled in college classes in the Air Force as soon as she was able. After 12 years she had a daughter, was divorced, and still did not have a college degree. She decided that if she wanted to "make it anywhere in life" she would need to 
finish her education. Amy sometimes wonders if leaving the military to pursue a college degree was the right decision. Her promise to herself to complete this goal is one of the factors that motivate her to continue.

Scott, Amy and Andrew all see utility in their specific degree programs. As he neared the end of high school Scott realized he did not have the skills or education to pursue a meaningful career. He also did not have a specific career in mind and thus was unsure what course of study to pursue in college. But he feared that if he did not attend college he would be faced with a dead-end job. He decided to join the Navy as a way to postpone that outcome. While he was in the Navy, Scott discovered a hobby that eventually led him to a prospective career. Scott recognizes that he needs an engineering degree to work in the area that has captured his interest. The promise of a fulfilling career is one factor that motivates him to persist in school.

Andrew recognizes that he needs an undergraduate degree in order to progress to a graduate program, and he also sees value in his specific degree area in that it will prepare him for his future career. He believes he will continue on to a doctoral program in psychology. He understands the utility of this first step.

Amy might not have returned home to mid-Missouri for school if it weren't for the fact that the university has a nationally known program in her area. She misses her friends and her daughter. But the international reputation of her degree program helps her to feel like her sacrifices are worthwhile.

All four students are also continuing their degree program at the university because the alternatives are not acceptable. These include issues of relocation, loss of 
investment and proximity of completion. Lillian has less than 25 credit hours remaining to complete her bachelor's degree. She is so close to finishing that quitting now would mean a big loss in terms of the time, energy and money she has invested. The tuition benefit from her job induces her to continue at the university instead of transferring to one of the other schools in the area. The proximity of her completion date also motivates her to continue in the face of a variety of obstacles (health issues, the transition to an allonline format in her degree program). Because the alternatives (quitting, transferring) are unacceptable, Lillian is persisting at the university.

Amy would sustain a similar loss if she were to leave the university. She has already invested substantial time and energy. Her degree program is one of the top three in the country. She is excited about her classes and can tell that her program is preparing her well. Because of this preparation she has obtained a meaningful and exciting parttime job in the Air National Guard in her area of interest. If she were to transfer or drop out she would lose the prestige of a degree from MU as well as internship and networking opportunities.

Scott and Andrew would lose their investment of time and energy if they left the university. Andrew originally enrolled at the university in order to live near his father. Subsequently his father has died, but Andrew has established substantial support circles including friends, roommates, and professional contacts through the Service Learning office on campus and through his volunteer job at Welcome Home. To leave the university would mean a loss of time and effort invested, but more importantly a loss of relationships he has established. These alternatives are not acceptable to Andrew. 
Scott's program is academically rigorous and at times he feels like giving up. During those times he reflects back on his time in the military. Returning to the Navy or working in a dead-end job are not acceptable alternatives for Scott. He wants a meaningful career and perceives this degree as being important to his future. Also, Scott has financial and emotional ties to mid-Missouri. If Scott were to transfer to another school he would lose the financial benefit of living with his sister. He has also stated that it is important to him to be close to home. Leaving mid-Missouri and the university would represent significant financial and emotional hardships for Scott. 


\section{Discussion}

This study sought to explore the personal and institutional factors that both support and impede the persistence of undergraduate military veteran students. In this section I will discuss the personal obstacles these students encountered as they return to the classroom, the personal factors that helped them to overcome these obstacles, and the institutional factors that are supporting or impeding their efforts to persist. I will also discuss limitations of the study and implications for policy, practice, and future research.

A great deal of research has been conducted on the factors that influence persistence for traditional undergraduate students. Tinto’s Student Integration Model (1975, 1987, 1993) and Bean’s Student Attrition Model (1980, 1981, 1982) found that academic and social integration, along with goal commitment, were the most important variables involved in students’ persistence behavior. Institutional commitment (Bean’s “intent to leave”) is another significant variable. For underrepresented students (minorities and first-generation college) peer support was found to be especially important, as well as academic involvement (Dennis et al., 2005; Douglas, 1998; Thayer, 2000; Velazquez, 1998).

Research on nontraditional students has shown that academic integration (fostered through academically related activities with faculty and peers) is the most significant factor supporting persistence for this group (Bean \& Metzner, 1985; Prather \& Hand, 
1986). Sufficient financial support for school and living expenses (including childcare), support from family and others, and goal commitment are also critical factors (Bean \& Metzner, 1985; Brown, 2002; Chartrand, 1992; Cini \& Fritz, 1996; Donaldson \& Graham, 1999; Fairchild, 2003; Prather \& Hand, 1986).

The military veteran students in this study are affected by many of the same factors that have an impact on both traditional and nontraditional students. Personal factors that are challenging these students’ persistence efforts include academic difficulties, a struggle to balance competing demands and roles, the transition to civilian life, and a longing for more meaningful support from family and classmates. Personal factors supporting persistence for these students include positive support received by these students, goal orientation, and the personal qualities they developed in the military that are helping them to overcome obstacles and persevere. Institutional efforts in the form of academic assistance and veterans programming are helping to support persistence efforts. A lack of institutional support for nontraditional students (e.g., childcare, afterhours availability of resources) as well as spotty communication to veteran students and employees present challenges to these veteran students.

\section{Personal Factors that Impede Persistence}

One of the most surprising results in this study was the academic challenges these students faced in returning to the classroom. All four students compared their abilities with the traditional undergraduate students who came to college straight from high school and therefore did not have a break in their education. Amy, Andrew and Scott felt like their academic skills and habits had gotten "rusty," with math being especially 
challenging. Scott and Amy wished they had done a better job preparing for college. They felt they lacked the necessary academic foundation. All four found the quick pace of the college classroom to be daunting and were surprised by the advances in technology.

These sentiments echo those of both first-generation and nontraditional students. Both groups have been characterized as having inadequate preparation for college in terms of academic skills, or lack of confidence about those skills. First-generation students are also characterized by lacking a full understanding of what to expect in college (Brown, 2002; Dennis et al., 2005; Donaldson \& Graham, 1999; Kasworm \& Pike, 1994; Kilgore \& Rice, 2003; Lohfink \& Paulsen, 2005; Pascarella et al., 2004; Thayer, 2000).

Another personal obstacle faced by all four students was the struggle to balance the demands of the classroom with their external obligations. Andrew's family crises, combined with his struggles with advanced math classes and a car accident, took such a toll that he was dismissed from the university for a period of time. Amy and Lillian have had to come to terms with taking time away from their children in order to devote time to school. Lillian's job and health issues also challenge her ability to stay on top of her academics. And Scott spoke of having to figure out what could fall "by the wayside."

This struggle to balance competing roles and demands on their time and energy is something many nontraditional students experience. Nontraditional students may feel a conflict with their multiple roles as student, parent, spouse and employee (Brown, 2002; Donaldson \& Graham, 1999; Fairchild, 2003; Kasworm \& Pike, 1994). Bean and 
Metzner (1985) found that “environmental variables” such as these (as well as financial issues and employment demands) had a direct effect on nontraditional students' intent to leave and thus an indirect effect on the decision to drop out.

Another factor that emerged in this study, and one that is unique to this group, is the challenge of making the transition from daily life in the military to life as a civilian on a college campus. This transition has parallels to the transition that traditional undergraduate students experience when they leave home and move to a residential campus (Astin, 1993, 1999; Bean, 1982, 1985; Pascarella \& Terenzini, 1983, 2005; Tinto, 1975, 1987, 1993).

Traditional students leave their hometowns, friends and family behind and join a brand-new community in which many norms and expectations are new. This transition may be especially challenging for minority and first-generation students for whom the college environment may be somewhat alien (Dennis et al., 2005; Douglas, 1998; Pascarella et al., 2004; Rendon et al., 2000; Richardson \& Skinner, 1992; Thayer, 2000; Tinto, 1993; Velasquez, 1998).

But aspects of this transition are unique for students who have been in the military. The students in this study are transitioning from a highly structured, unique environment with its own language, routines and demands to a much more fluid environment with different expectations and goals. Andrew and Scott both mentioned that there was no drill sergeant making them go to class. Scott mentioned the difficulty of leaving behind “military thought process.” He is struggling to learn how to act like a civilian. And Amy and Lillian spoke of leaving behind an important community with 
important resources such as childcare, as well as roles of significant responsibility and status.

It is worth noting that both Andrew and Scott are reticent to reveal their status as military veterans. For Scott especially there seems to be an effort to walk away from that piece of his history. He is concerned that the behaviors he developed in the military will damage the civilian relationships he is developing. He says he is proud of his service but does not want to be the victim of stereotyping. Andrew is more willing to reveal his status and is involved with veterans' activities on campus. But he still guards against situations where someone may ask whether or not he ever killed someone.

It is not unusual for college students to grapple with questions of whether to share a part of who they are. Examples include multiracial students who "pass” for one race, homosexual students who are still "in the closet," and students who may try to hide that they are from low-income families. It is also not unusual for veterans to be asked insensitive questions or to be stereotyped (DiRamio et al., 2008). Like these students, Scott and Andrew are carefully navigating the options when it comes to revealing this important part of their identity.

All four of the students in this study mentioned the importance of support from significant others including family, friends, classmates, and mentors. Yet they did not seem to feel that their support was as robust as they would have liked. Additionally, two of these students said their most meaningful sources of support lived far away from the university. 
Support from significant others is recognized as important for both traditional and nontraditional students (Astin, 1993, 1999; Bean, 1980, 1982; Brown, 2002; Donaldson \& Graham, 1999; Pascarella \& Terenzini, 1983, 2005; Prather \& Hand, 1986; Tinto, 1975, 1987, 1993). This support can come from a variety of sources - family, friends, faculty, classmates, mentors and even children. For traditional students it is assumed that an important source of support is the family.

Scott, Andrew and Amy mentioned receiving support from their family. Scott lives with his sister in a nearby small town. This helps to reduce his expenses and allows him to be close to his family, something he missed a great deal while in the Navy. Scott reports that his family supports his goal of obtaining a college degree. However his brother-in-law disparages Scott when he begins speaking with passion about ideas he is learning in school. ("You're just trying to sound intelligent.")

Amy's mother also supports her goal of a college degree, but is so unfamiliar with the nature of the college experience that Amy cannot have a meaningful conversation with her. Additionally, Amy has two younger siblings at home and who receive the bulk of her mother's energy and attention. Amy wishes she had someone to "send the grades home to" and who could share in her successes with a deeper understanding.

Andrew's family also supports his goal of a college degree. His mother and two of his sisters (all of whom live in Texas) seem genuinely happy for him. However three of his family members (brothers with felony convictions) are selfish in their support. They hope to tap into Andrew as a source of financial support now and in the future. 
These three students are first-generation college students. Their parents, and in most cases their siblings, do not have four-year college degrees and are therefore very unfamiliar with the nature of these students' experiences in school (Ishitani, 2003; Jones, 2001; Ringgenberg, 1989; Thayer, 2000; Velazquez, 1998). While none of these students experience opposition from their families for attending college, they long for more robust, knowledgeable, authentic support from this important source.

These three students (Amy, Andrew and Scott) are also attending classes full-time during the day, which is characteristic of traditional students. Traditional students typically develop networks of friends and classmates through classes and involvement in campus activities. Such peer support has been shown to be very important for traditional students, especially for minority and first-generation students. Peers can provide knowledge of the system that parents cannot offer. They can explain policies, help understand and locate campus resources, help with class selection, and otherwise help each other navigate the college or university system (Dennis et al., 2005; Douglas, 1998).

Amy and Scott find it very difficult to tap into a network of peers. Amy hears other students talk about having a group of friends who give them advice about classes and professors. She wishes she had a network of classmates who could help her navigate her academic program, and with whom she could commiserate about school. She also recognizes that she is not as proficient with technology as her classmates and longs for assistance in this area.

For Scott, a long commute to and from his sister's house eats up two hours of every day. This means he is unable to take advantage of academic and social activities 
outside of class. Scott describes himself as introverted and shy, but he does long to live in closer proximity to other students. He believes he is missing out on important professional networking opportunities by living so far away.

Though Amy and Scott long for a greater social or professional support system from their classmates, they do not believe that relationships with these fellow students would be truly fulfilling. They are caught in the middle. Their classmates are significantly younger than them so they differ in their perspectives, interests and activities. But they feel lonely and wish they had classmates who were closer in age and experience they could be friends with.

Andrew feels less isolated and more engaged on campus compared to Amy and Scott. Andrew has a core group of friends that he met through classes and other activities on campus He also lives with fellow college students. Andrew participates in a variety of campus activities and uses campus resources (e.g., the Veterans Center, the Black Culture Center, the gym). This means his campus involvement is very similar to that of a traditional college student.

While traditional college students find the center of their social life on campus through residence halls, study groups and other activities, nontraditional students do not generally look to the campus as the locus of their social life. They often have other networks outside of campus for social support (Chartrand, 1992; Donaldson \& Graham, 1999; Farabaugh-Dorkins, 1991; Graham \& Gisi, 2000; Kasworm \& Pike, 1994).

Lillian fits the profile of a nontraditional student and does not look to the campus to meet her social needs. However, she also misses connecting with fellow students. At 
one time Lillian was a full-time student who attended classes on campus during the day. She enjoyed interacting with fellow students and walking around campus. Now she is in the evening program which means all of her classes are online. She no longer has the opportunity to interact with classmates in person. While it does not seem like Lillian perceived her classmates to be close friends, she did find the interaction enriching. Additionally, Lillian's work schedule prevents her from attending veterans' events so she is missing out on those social opportunities as well. Lillian feels isolated and believes her educational experience has been severely diminished. This experience is not uncommon for nontraditional students. Services and activities that such students need or want to take advantage of often are only offered during regular business hours (services) or later in the evening (activities). This may be convenient for full-time residential students but it is not for others (Brown, 2002; Fairchild, 2003; Giancola et al., 2008; Rice, 2003).

Amy and Lillian both mentioned that their most important friends live far away. Lillian's best friend is in Guam. She keeps up with her through Facebook and plans to go see her upon graduation. Similarly, Amy said the people who understand her best are the friends she knew in the Air Force. She knows that she might be distracted from her school work if those friends lived nearby, and she acknowledged that she can call any of these individuals on the phone. But having good friends far away is not the same as having someone close by for casual social activities. 


\section{Personal Factors that Support Persistence}

Though aspects of these students’ support are not as substantial as they wish, they do receive important support from other sources. Additionally these students’ goal orientation and the skills and habits they developed through military service combine to help them persevere in completing their degrees.

Just as family and peer support is important for students, so is support from other quarters (Astin, 1993, 1999; Bean, 1980, 1982; Pascarella \& Terenzini, 1983, 2005; Tinto, 1975, 1987, 1993). The cumulative nature of this encouragement seems to help offset the less-than-ideal support these students receive from family and classmates.

For Amy, a surprising source of support has been a grandfather who lives nearby. Though they were not close when she was growing up, he now calls her on a regular basis to encourage her college efforts. Amy is gratified at this development. She also seems to have a good roommate situation. Though they don't get to socialize a great deal, Amy enjoys this woman's company and feels like she is more of a peer than her classmates. Amy also mentioned an officer who became a mentor for her. He encouraged her to quit the Air Force and follow her dream of obtaining a college degree. Even thought she does not have regular contact with him she is bolstered by his confidence in her and reflects on that friendship when she needs to boost her confidence and determination.

Andrew has found a core group of friends on campus and seems to have a robust social life. Andrew is also the only one of these students who seems to have had consistent interactions with faculty. While he was enrolled in advanced math classes 
Andrew needed a great deal of help with course work. He reports having good experiences with faculty when he sought assistance. Andrew also mentioned the guidance he has received from a friend from home who is a few years older than him and is the pastor at his church. This friend has identified positive attributes in Andrew and has encouraged him to follow a path in social service.

Lillian has a supportive supervisor who recognizes the challenges Lillian faces with her age and health (she gets tired more easily and finds it harder to concentrate). This woman has allowed Lillian to revise her schedule to work around her classes.

Two students in this study, Amy and Andrew, receive important professional and social support from the extracurricular activities in which they are engaged. These activities provide a tangible connection between their course work and their professional goals. This connection is helpful in student persistence as it reinforces a commitment to the goal of achieving a college degree. These activities also provide social support and mentoring, which has been shown to be important for both traditional and nontraditional students (Astin, 1993, 1999; Bean, 1980, 1982; Chartrand, 1992; Cini \& Fritz, 1996; Pascarella \& Terenzini, 1983, 2005; Prather \& Hand, 1986; Tinto, 1975, 1987, 1993).

Another factor that provides enormous advantage to these students is the fact that they have identified important personal and professional goals. If students are strongly committed to the goal of obtaining a college degree, or if they believe that the degree they are seeking has sufficient utility, or that the available alternatives are undesirable, they will likely persist to degree completion (Bean \& Metzner, 1985; Brown, 2002; Cini 
\& Fritz, 1996; Donaldson \& Graham, 1999; Prather \& Hand, 1986; Tinto, 1975, 1987, 1993).

Scott is very happy (perhaps relieved) to have found an area of interest that can lead to a challenging and fulfilling career. Amy is also excited to have found a career path that will provide financial security and will be something she enjoys. She is also excited to finally be pursuing a lifelong goal. Andrew struggled with his initial choice of major but has found something that he believes is a better fit for his abilities. He is also glad that he will be able to help fellow veterans. Lillian is also happy to be close to achieving a lifelong goal. The value these students place on a college degree is one thing that helps them to persevere in the face of other challenges.

Perceptions of degree utility are also important in student persistence decisions (Bean \& Metzner, 1985; Brown, 2002; Cini \& Fritz, 1996; Donaldson \& Graham, 1999; Prather \& Hand, 1986). Though a student might not value a college degree just for the sake of the degree, they may believe that the specific college degree they are pursuing will be useful. Perceptions regarding the reputation of the school, advice from an employer, or messages they have received from the media or significant others can all influence a student's belief that a particular degree will make a difference in their career trajectory (Brown, 2002; Cini \& Fritz, 1996; Donaldson \& Graham, 1999; Prather \& Hand, 1986).

Amy is attending a program that is nationally recognized as one of the top three for her interest area. This provides a greater sense of value to pursuing this specific degree at this university and leads to a greater commitment to the institution. Scott and 
Andrew are unconcerned about the reputation of the university in their fields of interest. But they do both believe that their particular degree is a good starting point for their career goals. They also value the quality of the education they are receiving.

Finally, persistence at a particular institution might result because the student perceives that there are no acceptable alternatives (Bean \& Metzner, 1985; Brown, 2002; Cini \& Fritz, 1996; Donaldson \& Graham, 1999; Prather \& Hand, 1986). For example, a student might be unwilling or unable to relocate, in which case they may decide to continue at their current institution. Students may also decide the costs of dropping out or transferring to another school are too great (e.g., loss of investment in terms of time and energy committed thus far, possible loss of credits upon transfer, loss of established relationships on campus). Finally, students may consider the proximity to degree completion. If a student has a short time to degree completion she or he may decide it is worth the effort to complete the process at the current institution (Brown, 2002; Cini \& Fritz, 1996; Donaldson \& Graham, 1999; Prather \& Hand, 1986).

Lillian feels strongly that she has no other choice but to finish her bachelor's degree at the university. She is unwilling to relocate to another city. Her university employment provides a substantial subsidy on the cost of tuition; transferring to another school would create a financial burden. And she is within just a few hours of degree completion. She is angry that the evening program is now only offered online but she plans to continue to degree completion because there are no other good alternatives. 
Andrew is very engaged with the university campus. His relationships with faculty, staff and friends are important to him. Leaving the university would mean leaving those behind. He would lose the benefits associated with those relationships.

In addition to their goal commitment, these students all spoke of the personal qualities they developed through their military service as being part of the reason for their success. They all developed skills in prioritizing and time management. But they also developed less tangible qualities such as maturity, confidence, motivation, independence, and a refusal to settle for things or situations they don't want. They also all developed a broader perspective on the world and a genuine appreciation for people different from them. As one student said, such qualities give these students an edge.

Nontraditional students often have a broader perspective on life and are likely to have specific academic and professional goals in mind when they enroll in college. They are also more likely to be better managers of their time and will be good at making connections between their prior knowledge and what they are learning in the classroom (Brown, 2002; Cini \& Fritz, 1996; Donaldson \& Graham, 1999; Kasworm, 2003; Prather \& Hand, 1986). These personal qualities can help a student overcome other hurdles such as poor academic preparation, distance since high school, or family and work demands.

All four participants in this study credited their growth and maturation in the military as being beneficial (e.g. experience with hard work, an ability to multitask, and a broadened and mature perspective on the world). Scott developed skills in time management and prioritizing through his experience in the Navy. He is surprised at the work load in college; it is more difficult than he imagined. As he says, he is constantly 
weighing which tasks have to be done and which can "fall by the wayside." He acknowledges that without the maturity he developed in the Navy, as well as more tangible skills, he would not be successful in college. Amy also reflected on the work habits and endurance she developed in the service. She is used to getting up very early for work and then working hard until a job was completed. She has continued this practice in her academic life.

These students also have the personal discipline to reach their goals. What these students may lack in terms of academic and technological currency they make up for in sheer determination, drive and discipline. Amy credits the Air Force for helping her to become a person who does not give up in the face of adversity. She describes this as "growing up in an environment where, you know, failure is not an option." Scott reflected this mindset when he described setting a goal (such as earning a college degree) and then working to achieve that goal. "I have to sit down ahead of time and make that decision and then never look back. There’s no backing out.”

\section{Institutional Factors that Support Persistence}

Research on student attrition has focused on institutional responses, with an emphasis on programs and services that help to foster academic and social integration (Astin, 1993, 1999; Bean, 1980, 1982; Bean \& Metzner, 1985; Pascarella and Terenzini, 1983, 2005; Tinto, 1975, 1987, 1993). The University of Missouri already has a robust set of programs and services aimed at fostering academic and social integration including a summer orientation program (Summer Welcome), Freshmen Interest Groups (FIGs), a first-year experience course (Learning Strategies), numerous student groups, 
undergraduate research opportunities, and a variety of academic support services (individual and group tutoring and student advising, to name two).

The limited research on veteran students shows that appropriate campus services make a difference in the ease of their college experience (Ford et al., 2009; Johnson, 2009; Lokken et al., 2009; Summerlot et al., 2009). Since 2009 MU has provided veteran-focused versions of some services including outreach to veterans during Summer Welcome, a Veterans Resource Center, a veteran student group, free individual tutoring, and a section of Learning Strategies.

Three of the students in this study (Amy, Scott and Andrew) took advantage of these veteran-specific services to varying degrees and found them to be helpful overall. The processing of GI Bill payments that is handled by the Veterans Center was cited by all three students as an exceptional service. The free tutoring for veterans was also cited by these three as a valuable option, though not all had participated. Learning about veterans services on campus through the Summer Welcome program was also helpful. When an institution provides services to students that either help remove bureaucratic hurdles or help students achieve academically and integrate socially, students perceive that the institution cares about their success. This in turn leads to greater institutional commitment which can help foster persistence (Astin, 1993, 1999; Bean, 1980, 1982; Pascarella \& Terenzini, 1983, 2005; Tinto, 1975, 1987, 1993).

Financial struggles can also pose a significant challenge for both first-generation and nontraditional students. In research on persistence for both groups, socioeconomic status and financial support have been identified as factors that can impede students' 
persistence to degree completion (Brown, 2002; Dennis et al., 2005; Giancola et al., 2008; Ishitani, 2003; Jones, 2001; Lohfink \& Paulsen, 2005; Pascarella et al., 2004; Prather \& Hand, 1986; Thayer, 2000). For three of the members of this group the GI Bill has been a significant source of financial assistance. Funding through the GI Bill is the reason these three students can attend college, but sorting through the red tape involved in acquiring funding might mean some of these students would give up in frustration. All three cite the coordination of benefits provided by the Veterans Center as being a significant institutional factor that helps them in their quest to earn a college degree.

Lillian is not eligible for GI Bill benefits but is very grateful for the support provided to her as an employee through the university's tuition assistance program.

\section{Institutional Factors that Impede Persistence}

The university provides a robust and varied set of services, programs and activities for traditional students. However, these are only offered during regular business hours (for services) or later in the evening (for programs and activities). This structure is convenient for full-time, residential students but nontraditional students find such limitations to be a challenge (Brown, 2002; Fairchild, 2003; Giancola et al., 2008; Rice, 2003).

Lillian especially feels the impact of such a structure. She works in an off-campus location that is not within walking distance of the university. She would like to come to the Veterans Center over lunch but parking is nearly impossible to find. She is unable to participate in evening activities because she must be logged in for her online courses. She 
is also not a part of campus communications regarding veterans' activities and so is unaware of any weekend options.

Amy and Lillian have both struggled to balance the competing demands of school work and parenting. Childcare opportunities through the university are very limited which means parents must struggle to find trustworthy, affordable, and convenient care for their children. This puts a burden on these students. The university also does not have an organized network of student parents. Such an organization could provide support for student parents and an opportunity to share transportation and other duties. A lack of services for students who are parents is one institutional factor that is impeding the persistence efforts of these students.

Research with both traditional and nontraditional undergraduates has shown that academic involvement and success are important in student persistence (Astin, 1993, 1999; Bean, 1982, 1985; Chartrand, 1992; Cini \& Fritz, 1996; Donaldson \& Graham, 1999; Farabaugh-Dorkins, 1991; Graham \& Gisi, 2000; Kasworm \& Pike, 1994; Pascarella and Terenzini, 1983, 2005; Prather \& Hand, 1986; Tinto, 1987, 1993). An important factor in this involvement is the relationships students build with faculty. None of these students reported negative interactions with faculty. One student (Andrew) reported building relationships with several of his instructors through reaching out for assistance with course work. Scott had not contacted any professors for assistance but anticipates a positive response if he does. Amy did reach out to one of her professors by sending an acknowledgement of how helpful his class was but she did not report receiving a response. Lillian struggled with a challenging exchange with a classmate 
through their Blackboard site and received a message from her professor supporting her in that effort. Though these students are persisting to degree completion in spite of limited relationships with faculty, it is possible that deeper relationships with faculty might make the college experience more enriching for these students.

\section{Limitations of the Study}

Qualitative studies do not require a large number of participants. However the small sample size in this study is not ideal. It is likely that a greater number of interviews would have provided richer data and increased insight into the experiences of veteran students. This study was exploratory in nature. It is hoped that even this small sample will provide new information about this population of students.

None of the participants in this study were combat veterans, nor did any of these students have disabilities related to their military service. It is possible that participants with those characteristics would bring to light perspectives that are unique to those groups.

It is unclear whether the unwillingness of the student leader of MSVA to assist in recruiting students for this study had an impact on availability of veteran participants. It is possible that a segment of the veteran student population ignored this research opportunity at the behest of this student leader. Important perspectives may have been lost as a result. It would be wise for future researchers to become personally acquainted with student officers in the MSVA group in order to explain the research project. This could help alleviate fears and affirm privacy protections for student veterans. Conducting 
information sessions at the Veterans Center and through MSVA meetings might also garner more participants.

\section{Implications for Practice and Future Research}

One of the main obstacles faced by these students was reintegration into the academic milieu. On this campus a first-year experience course called Learning Strategies is offered as a way to assist students with the transition to college. For two semesters a veterans-only section was offered but recent enrollment has not been sufficient for the course to continue. It is unclear if low enrollment is due to lack of marketing to veterans or if it is due to other factors. (Are transition needs being met through other services? Are students encountering scheduling conflicts? Is the course not perceived as useful?) It would be worthwhile for the campus to explore the reasons for this low enrollment and determine if the course could be offered again.

In fact, the university should explore a variety of options to assist student veterans in their transition to campus. For example, one option that could be offered in addition to or instead of the FYE seminar would be a weekly or monthly open discussion session for veterans. It could be facilitated by an undergraduate advisor and could provide an opportunity for veteran students to discuss their reintegration experiences.

Military veteran students who enroll at the university should be flagged in the student information system. If the university wishes to welcome these students and communicate policies and opportunities to them it would be helpful for the Registrar's office to send a list of veteran students to the Veterans Center each semester. A listserv could be built and maintained which would allow veteran students to receive regular 
emails. These emails could include invitations to campus activities, including participation with MSVA, and notification of both academic and veterans-related deadlines (e.g., dates for GI Bill submission). A secondary listserv could include faculty and staff who are also veterans so that they may participate as well.

Through such an effort it would also be possible to connect student veterans with faculty and staff who have also served. Relationships with faculty and staff are important to students’ academic involvement. Greater involvement is predictive of persistence behavior. Such a listserv would allow employees like Lillian to engage with other veterans, both students and employees. It would also allow the other three students to identify additional sources of support.

Andrew’s positive experience with the campus’s Service Learning office demonstrates the value of connecting students with opportunities to volunteer in the community. Such opportunities allow student veterans to put to work some of the skills they learned while in the military. The students also have a chance to develop supportive relationships and receive positive feedback for their involvement. It would be smart for the university to communicate the availability of the Service Learning program to all incoming veteran students.

Considering the importance of goal commitment and personal discipline in the success of these students, future research on the goal orientation of veteran students might provide important insights that would help this institution support the persistence efforts of this population. It might be useful to develop a screening instrument for 
military veteran students that advisors could use in their efforts to find ways to motivate such students. 


\section{Conclusion}

The number of veteran students will continue to grow in the foreseeable future yet little research has been done on this population of students. Research examining the factors that have an impact on persistence for this group of students is still nascent.

This research has demonstrated that services and programs geared towards veterans (including advising, tutoring, and assistance with the GI Bill) are important to these students. Support from significant others, especially mentors, is important. Faculty and staff can play a role here by providing encouragement of veteran students' efforts. Finally, the goal orientation and personal discipline and determination evidenced by this group are important factors in their perseverance. Again, campus programming as well as support from faculty and staff can help these students identify and clarify their goals and can encourage their efforts.

While it is still unclear overall whether military veteran students have more in common with traditional undergraduates or nontraditional students, or if they comprise a unique group that straddles both populations, it appears that the students in this study share qualities with both groups. Just as nontraditional students cannot be treated as a homogeneous population it appears that military veteran students are also not a homogeneous group. As the university seeks to create programs and policies that address the needs of this population it will be important to train faculty and staff to treat veteran students as individuals. 


\section{Appendix A}

\section{Veterans Research Survey}

Thank you for your interest in this research study on undergraduate veteran students. Please take a minute to complete this survey, and then return it via email to pickensm@missouri.edu. I will get back in touch with you shortly.

(Note: In areas where you fill in the blanks, the boxes accept as much text as needed.)

1. Age: $\square$ Under $24 \quad \square 24$ to $35 \quad \square 36$ and older

2. Gender:

3. Hometown:

4. Relationship status:

$\begin{array}{ll}\square \text { Single } & \square \text { Married/Partnered } \\ \square \text { Separated } & \square \text { Divorced } \square \text { Widowed }\end{array}$

5. Do you have children? $\square$ Yes $\square$ No

Ages:

6. Are you employed? $\square$ Yes $\square$ No

On or off campus?

Hours per week?

7. Do you live on campus?

$\square$ On campus $\square$ Off campus

8. What semester and year did you begin at MU?

9. Are you enrolled full or part time?

Full time

Part time

10 . What is your major/area of interest?

11 . What is your branch of service?

12. Year of enlistment/Age at enlisting:

13. Years in/where stationed:

14. Were you ever deployed? $\square$ Yes $\square$ No

- When/where?

15. Did you ever see active duty?

Yes $\square$ No

- When/where?

16. Year of discharge/Age at discharge: 


\section{Appendix B}

\section{WAIVER OF DOCUMENTATION OF CONSENT}

\section{INVESTIGATOR's NAME: MARTHA PICKENS \\ PROJECT \# 1203492}

\section{STUDY TITLE: AN EXPLORATION OF FACTORS AFFECTING PERSISTENCE OF UNDERGRADUATE MILITARY VETERAN STUDENTS AT THE UNIVERSITY OF MISSOURI.}

I would like to ask you to participate in a study that involves research.

The purpose of this study is to explore the institutional and personal factors that help veteran students stay in school and finish their degree program, vs. those factors that might impede students’ progress.

For this study, you will be interviewed about your experience as a student at MU and about your educational goals. The purpose of this study is not to seek in-depth information about your military experiences. Some questions about your service history will be asked as they relate to your experiences at the university. The interview will last anywhere from 30 to 60 minutes; you are free to end the interview at any time without consequence.

We are asking approximately five to 10 subjects to participate in this study.

The study staff may withdraw you from the study at any time after explaining to you the reason for withdrawal.

Participation is voluntary and your decision not to participate will not involve any penalty or loss of benefits. We do not anticipate there will be any risk to you as a result of your decision to participate in this study. There are no costs associated with participating in this study.

If you choose to participate, all information collected during interviews will remain private. It will be used for research purposes only. An audio recording of the interview will be made and this recording will be transcribed. This will help the researcher to keep track of important information from each interview. Audio recordings and transcripts will be coded with an identifying number. These materials will be kept locked in a secure location and will be kept separate from materials identifying study participants. Your name will not be used when the research results are reported, and other identifying information about you will be disguised in the research report. 
If you agree to take part in this study, you may expect to benefit to the extent that you are contributing to knowledge about the experience of veteran students at the University of Missouri.

In recognition of the valuable contribution of your time in this research effort, you have the option to enter your name in a drawing for one of five \$30 gift cards to the University Bookstore.

If you have any questions regarding your rights as a participant in this research and/or concerns about the study, or if you feel under any pressure to enroll or to continue to participate in this study, you may contact the Campus IRB office at Campus Institutional Review Board, 483 McReynolds Hall, University of Missouri, Columbia, MO, 65211. The web site is available at www.research.missouri.edu/cirb/index/htm and the phone number is $573-882-9585$.

If you have any problems or questions, you may contact Martha Pickens, pickensm@missouri.edu, or her supervisor Prof. David Bergin, bergind@missouri.edu.

A copy of this script will be given to you to keep. 


\section{References}

About Mizzou, University of Missouri. (n.d.) Retrieved from http://missouri.edu/about/

Ackerman, R. DiRamio, D., \& Mitchell, R.L.G. (2009). Transitions: Combat veterans as college students. In R. Ackerman and D. DiRamio (Eds.) Creating a veteranfriendly campus (pp. 5-14). In New directions for student services, 126. doi: 10.1002/ss.310.

Astin, A.W. (1993). What matters in college? Liberal Education, 79(4), 4-15.

Astin, A.W. (1999). Involvement in learning revisited: Lessons we have learned. Journal of College Student Development, 40, 518-529.

Avery, C. E. (1946). Veterans' education in the universities. Journal of Higher Education, 17, 359-363.

Bauman, M. (2009). The mobilization and return of undergraduate students serving in the National Guard and Reserves. In R. Ackerman and D. DiRamio (Eds.) Creating a veteran friendly campus (pp. 15-23). In New directions for student services, 126. doi: $10.1002 /$ ss.310.

Bean, J.P. (1980). Dropouts and turnover: The synthesis and test of a causal model of student attrition. Research in Higher Education, 12, 155-187.

Bean, J.P. (1981). Student attrition, intentions, and confidence: Interaction effects in a path model. Part I, the 23 variable model. Paper presented at the annual meeting of the American Educational Research Association (Los Angeles, CA, April 13-7, 1981). ERIC Document ED202443.

Bean, J.P. (1982). Student attrition, intentions, and confidence: Interaction effects in a path model. Research in Higher Education, 17, 291-320.

Bean, J.P., \& Metzner, B.S. (1985). A conceptual model of nontraditional undergraduate student attrition. Review of Educational Research, 55, 485-540.

Bennett, M.J. (1996). When dreams came true: The GI Bill and the making of modern America. Washington, D.C.: Brassey's, Inc.

Blair, J. (1999, January 27). GI Bill Paved the Way for a Nation of Higher Learners. Education Week, 18, 32. 
Borus, J.F. (1975). The reentry transition of the Vietnam veteran. Armed Forces and Society, 2, 97-113.

Braxton, J.M. \& Lee, S.D. (2005). Toward Reliable Knowledge about College Student Departure. In A. Seidman (Ed.), College Student Retention: Formula for Student Success (pp. 107-128). Westport, CT: Greenwood Publishing Group.

Braxton, J., Sullivan, A., \& Johnson, R. (1997). Appraising Tinto's theory of college student departure. In J.C. Smart (Ed.), Higher education: Handbook of theory and research, vol. 12 (pp. 107-164). New York: Agathon Press.

Brown, S.M. (2002). Strategies that contribute to nontraditional/adult student development and persistence. PAACE Journal of Lifelong Learning, 11, 67-76.

Cabrera, A., Castaneda, M., Nora, A., \& Hengstler, D. (1992). The convergence between two theories of college persistence. Journal of Higher Education, 63(2), 143-164.

Cabrera, A.F., Nora , A., \& Castaneda M.B. (1993) College Persistence: Structural Equations Modeling Test of an Integrated Model of Student Retention. Journal of Higher Education, 64, 123-39.

Cabrera, A.F., Nora, A., Terenzini, P.T., Pascarella, E., \& Hagedorn. L.S. (1999). Campus racial climate and the adjustment of students to college: A comparison between white students and African-American students. The Journal of Higher Education, 70, 134-160.

Chartrand, J.M. (1992). An empirical test of a model of non-traditional student adjustment. Journal of Counseling Psychology, 39, 193-202.

Cini, M. \& Fritz, J.M.H. (1996). Predicting commitment in adult and traditional-age students: Applying Rusbult's Investment Model to the study of retention. ERIC Document ED401451.

Clark, D.A. (1998). The Two Joes Meet - Joe College, Joe Veteran: The G. I. Bill, college education, and postwar American culture. History of Education Quarterly, 38, 165-189.

Cleveland-Innes, M. (1994). Adult student drop-out at post-secondary institutions. The Review of Higher Education, 17, 423-445.

Cook, B.J. \& Kim, Y. (2009). From soldier to student: Easing the transition of service members to campus. American Council on Education; Serving Those Who Serve. Retrieved from 
http://www.acenet.edu/AM/Template.cfm?Section=HENA\&Template=/CM/Cont entDisplay.cfm\&ContentID=33233

Creswell, J.W. (2009). Research design: Qualitative, quantitative, and mixed methods approaches (3rd ed.). Los Angeles: Sage.

Defense Manpower Data Center. (2007). CTS deployment file baseline report (March 31). Washington, D.C.: Department of Defense.

Department of Defense Publications. (2009). Population representation in the military services: Fiscal year 2009 report. Washington, DC: Department of Defense. Retrieved from http://prhome.defense.gov/

Department of Veterans Affairs, GI Bill, Benefits. (n.d.) Retrieved from http://gibill.va.gov/resources/benefits_resources/benefit_comparison_tools.html

Dennis, J.M., Phinney, J.S., \& Chuateco, L.I. (2005). The role of motivation, parental support, and peer support in the academic success of ethnic minority firstgeneration college students. Journal of College Student Development, 46, 223236.

DiRamio, D., Ackerman, R., \& Mitchell, R.L. (2008). From combat to campus: Voices of student-veterans. NASPA Journal, 45, 73-102.

DiRamio, D., \& Jarvis, K. (2011). Veterans in Higher Education: When Johnny and Jane Come Marching to Campus. (ASHE Higher Education Report, Vol. 37. No. 3). San Francisco: Jossey-Bass.

Donaldson, J.F., and Graham, S. (1999). A model of college outcomes for adults. Adult Education Quarterly, 50(1), 24-40.

Douglas, K. B. (1998). Impressions: African American first-year students' perceptions of a predominantly white university. Journal of Negro Education, 67, 416-431.

Enrollment Summary, Fall, 2012. University of Missouri. Retrieved from http://registrar.missouri.edu/statistics/fall-2012/Fall-2012-EnrollmentSummarycombined.pdf.

Fairchild, E.E. (2003). Multiple roles of adult learners. In D. Kilgore \& P.J. Rice (Eds.) Meeting the special needs of adult students (pp.11-16). In New Directions for Student Services, 102. doi: 10.1002/ss.84.

Farabaugh-Dorkins, C. (1991). Beginning to understand why older students drop out of college: A path analytic test of the Bean/Metzner model of nontraditional student 
attrition. Association for Institutional Research, AIR Professional File, no. 39, pp. 1-12. Retrieved from http://www.airweb.org/page.asp?page=73\&apppage=85\&id=39

Faulkner, R.R., \& McGaw, D.B. (1977). Uneasy homecoming: Stages in the reentry transition of Vietnam veterans. Urban Life, 6, 303-328.

Field, K., Hebel, S. \& Smallwood, S. (2008, July 25). Cost, convenience drive veterans' college choices. Chronicle of Higher Education.54, A1-A14 (4 p).

Flowers, L.A. (2004). Examining the effects of student involvement on African American college student development. Journal of College Student Development, 45, 633654.

Ford, D., Northrup, P., \& Wiley, L. (2009). Connections, partnerships, opportunities, and programs to enhance success for military students. In R. Ackerman and D. DiRamio (Eds.) Creating a veteran-friendly campus (pp. 61-69). In New directions for student services, 126. doi: 10.1002/ss.310.

GI Bill Turns 62 Today. (2006, June 22). Retrieved from http://www.military.com/NewsContent/0,13319,102383,00.html.

Giancola, J.K., Munz, D.C. \& Trares, S. (2008). First- versus continuing-generation adult students on college perceptions: Are differences actually because of demographic variance? Adult Education Quarterly, 58, 214-228.

Graham, S. W., \& Gisi, S. L. (2000). Adult undergraduate students: What role does college involvement play? NASPA Journal, 38, 99-121.

Horan, M. (1991). Touching the Hearts and Souls of the Vietnam Warrior. ERIC Document ED343008.

Hurtado, S., \& Carter, D.F. (1997). Effects of college transition and perceptions of the campus racial climate on Latino college students' sense of belonging. Sociology of Education, 70, 324-345.

Hurtado, S., Milem, J., Clayton-Pederson, A., \& Allen, W. (1999). Enacting diverse learning environments: Improving the climate for racial/ethnic diversity in higher education. (ASHE-ERIC Higher Education Report, 1999, Vol. 26, No. 8.) Washington, D.C.: The George Washington University, Graduate School of Education and Human Development. ERIC Document ED430514. 
Ishitani, T.T. (2003). A longitudinal approach to assessing attrition behavior among firstgeneration students: Time-varying effects of pre-college characteristics. Research in Higher Education, 44, 433-449.

Johnson, T. (2009). Ensuring the success of deploying students: A campus view. In R. Ackerman and D. DiRamio (Eds.) Creating a veteran-friendly campus (pp. 5560). In New directions for student services, 126. doi: 10.1002/ss.310.

Jones, L. (2001). Creating an affirming culture to retain African-American students during the post-affirmative action era in higher education. In L. Jones (Ed.), Retaining African Americans in Higher Education (pp. 3-20). Sterling, VA: Stylus Publishing.

Kasworm, C.E. (2003). Setting the stage: Adults in higher education. In D. Kilgore \& P.J. Rice (Eds.) Meeting the special needs of adult students (pp.11-16). In New Directions for Student Services, 102. doi: 10.1002/ss.84.

Kasworm, C.E. \& Pike, G. (1994). Adult undergraduate students: Evaluating the appropriateness of a traditional model of academic performance. Research in Higher Education, 35, 689-710.

Kilgore, D. \& Rice, P.J. (2003). New directions for inquiry and practice. In D. Kilgore \& P.J. Rice (Eds.) Meeting the special needs of adult students (pp.11-16). In New Directions for Student Services, 102. doi: 10.1002/ss.84.

Lohfink, M.M., \& Paulsen, M.B. (2005). Comparing the determinants of persistence for first-generation and continuing-generation college students. Journal of College Student Development, 46, 409-428.

Lokken, J.M., Pfeffer, D.S., McAuley, J., \& Strong, C. (2009). A statewide approach to creating veteran-friendly campuses. In R. Ackerman and D. DiRamio (Eds.) Creating a veteran-friendly campus (pp. 45-54). In New directions for student services, 126. doi: 10.1002/ss.310.

Lundberg, C.A. (2003). The influence of time-limitations, faculty, and peer relationships on adult student learning: A causal model. The Journal of Higher Education, 74, 665-688.

Martinez, M.D. (2003). Missing in action: Reconstructing hope and possibility among Latino students placed at risk. Journal of Latinos in Education, 2, 13-21.

Merriam, S.B. (1998). Qualitative research and case study applications in education ( $2^{\text {nd }}$ ed.). San Francisco: Jossey-Bass. 
Metzner, B.S. \& Bean, J.P. (1987). The estimation of a conceptual model of nontraditional undergraduate student attrition. Research in Higher Education, 27, 15-38.

Nora, A., \& Cabrera, A.F. (1996). The role of perceptions of prejudice and discrimination on the adjustment of minority students to college. The Journal of Higher Education, 67,119-148.

Olson, Keith W. (1974). The GI Bill, the veterans, and the colleges. Lexington: University Press of Kentucky.

Pascarella, E.T., Pierson, C.T., Wolniak, G.C., Terenzini, P.T. (2004). First-Generation College Students, Additional Evidence on College Experiences and Outcomes, The Journal of Higher Education, 75(3), 249-284.

Pascarella, E.T., \& Terenzini, P.T. (1983). Predicting voluntary freshman year persistence/withdrawal behavior in a residential university: A path analytic validation of Tinto's model. Journal of Educational Psychology, 75, 215-226.

Pascarella, E.T., \& Terenzini, P.T. (2005). How college affects students: A third decade of research ( $2^{\text {nd }}$ ed.). San Francisco: Jossey-Bass.

Phinney, J.S., \& Hass, K. (2003). The process of coping among ethnic minority firstgeneration college freshmen: A narrative approach. The Journal of Social Psychology, 143, 707-726.

Prather, J.E. \& Hand, C.A. (1986). Retention of non-traditional students. Paper presented at the annual meeting of the Southern Association for Institutional Research, Pipestem, WV, October, 1986. ERIC Document ED274296.

Rendon, L.I., Jalomo, R.E., \& Nora, A. (2000). Theoretical considerations in the study of minority student retention in higher education. In J. M. Braxton (Ed.), Reworking the Student Departure Puzzle (pp. 127-156). Nashville, TN: Vanderbilt University Press.

Report of the Chancellor's Task Force for a Veteran-Friendly Campus. (2009). Columbia, MO: University of Missouri. Retrieved from http://www.moacrao.org/extern/conferences/PowerpointPresentations/2012Confer ence/VetFriendlyTaskforceReport.pdf

Rice, P.J. (2003). Adult student services office. In D. Kilgore \& P.J. Rice (Eds.) Meeting the special needs of adult students (pp.11-16). In New Directions for Student Services, 102. doi: 10.1002/ss.84. 
Richardson, Jr., R.C. \& Skinner, E.F. (1992). Helping first-generation minority students achieve degrees. In L. S. Zwerling, \& H. B. London (Eds.), First-generation students: Confronting the cultural issues (pp. 29-43). In New Directions for Community Colleges: No. 80. San Francisco: Jossey-Bass.

Ringgenberg, L.J. (1989). Expanding participation of student subgroups in campus activities. In D. C. Roberts (Ed.), Designing campus activities to foster a sense of community (pp. 27-37). In New Directions for Student Services: Vol. 48. San Francisco: Jossey-Bass.

Rumann, C.B., \& Hamrick, F.A. (2009). Supporting student veterans in transition. In R Ackerman and D. DiRamio (Eds.) Creating a veteran-friendly campus (pp. 2534). New directions for student services, 126. doi: 10.1002/ss.310.

Stake, R.E. (1995). The art of case study research. Thousand Oaks, CA: Sage.

Summerlot, J., Green, S.M., \& Parker, D. (2009). Student veterans organizations. In R. Ackerman and D. DiRamio (Eds.) Creating a veteran-friendly campus (pp. 7179). In New directions for student services, 126. doi: 10.1002/ss.310.

Thayer, P. B. (2000). Retention of students from first generation and low income backgrounds. U.S.; District of Columbia: Council for Opportunity in Education. ERIC Document ED446633.

Ting, S., \& Robinson, T.L. (1998). First-year academic success: A prediction combining cognitive and psychosocial variables for Caucasian and African American students. Journal of College Student Development, 39, 599-610.

Tinto, V. (1975). Dropout from higher education: A theoretical synthesis of recent research. Review of Educational Research, 65, 89-125.

Tinto, V. (1987, 1993). Leaving college: Rethinking the causes and cures of student attrition. Chicago: University of Chicago Press.

Tinto, V. (1998). Colleges as communities: Taking research on student persistence seriously. The Review of Higher Education, 21,167-177.

Toolkit for Veteran Friendly Institutions. (n.d.). American Council on Education; Serving Those Who Serve. Retrieved from https://vetfriendlytoolkit.acenet.edu/Pages/default.aspx

Velasquez, P. (1998). Cultural activities and campus involvement. U.S.; District of Columbia: National Council of Educational Opportunity Associations. ERIC Document ED420266. 
Yin, R.K. (2009). Case study research: Design and methods $\left(4^{\text {th }}\right.$ ed.). In Applied social research methods series: Vol. 5. Los Angeles: Sage. 